\title{
Ruminant phylogenetics: A reproductive biological perspective
}

\author{
William J. Silvia \\ Department of Animal and Food Sciences, University of Kentucky, Lexington, KY, USA 40546
}

\begin{abstract}
Summary
Phylogenetics is the study of evolutionary relationships among species. Phylogenies are based on the comparison of large numbers of characteristics among species. Traditionally, the field of phylogenetics was dominated by paleontologists so the characteristics studied were structural, often skeletal. The field of phylogenetics was revolutionized in the 1980s as scientists began using molecular data, first amino acid, then nucleotide sequences. This led to the inclusion of more characteristics and many more extant species in these analyses. We now have very well characterized phylogenies for most major groups of mammals, including the ruminants (Ruminantia, a suborder within Artiodactyla). The ruminants are traditionally divided into six families: Tragulidae (mouse deer), Moschidae (musk deer), Cervidae (true deer), Antilocapridae (pronghorn), Giraffidae (giraffes and okapis) and Bovidae (horned ruminants). Despite extensive research, some phylogenetic relationships within the Ruminantia have not been completely resolved. For example, the precise relationships among the six ruminant families is not clear. The relationship of cattle (Bos taurus) to other large bovids (gaurs, bison, yaks, etc.) remains to be determined. Ultimately, more extensive characterization and comparison of ruminant genomes will define these relationships. In the mean time, we may be able to use reproductive characteristics to help clarify some of the unresolved phylogenetic relationships. Reproductive characteristics can vary greatly among species. Much of this variation is recently evolved, making it particularly useful in defining relationships among closely related species or groups. Placentally expressed gene families, reproductive behaviors and even interspecies embryo transfer studies may provide novel ways to resolve the few remaining phylogenetic questions in ruminants. Recognizing that the vast majority of existing phylogenies are extremely accurate, reproductive biologists can use them to make more rapid progress in extending research from one species to another. Phylogenies also can provide a background to determine how specific reproductive characteristics evolved over time. Finally, phylogenetics and reproductive biology can be brought together to study the fundamental biological process of speciation. Speciation is the study of how new species arise. Establishing reproductive isolating barriers (variation) between a nascent species and its immediate ancestor is a fundamental part of the speciation
\end{abstract}


process. Much of the work in this area has been done using invertebrate species with very short generation intervals. Mammalian models to study speciation are severely lacking. Ruminants may be an ideal group in which to study this process since they have the two prerequisites essential to this type of work, 1) a large number of recently-evolved extant species and 2) well characterized and dated phylogenies. The body of fundamental research characterizing reproductive systems in a few ruminants is enormous. We are at a point where we can start to extend more of this research to other ruminant species to address the process of speciation, and perhaps other, fundamental biological questions.

\section{What is phylogenetics?}

Phylogenetics is the study of evolutionary relationships among species. Phylogenetic relationships are proposed based upon thorough, systematic and on-going comparisons of diverse characteristics. Thus, they are under continuous revision. Scientists had been classifying and organizing species based on the comparison of morphological characteristics since the 1700s. These types of comparisons were the basis for the first comprehensive taxonomic classifications by Carl von Linné (Linnaeus), Georges Cuvier, Richard Owen and others. To be clear, these authors were only using the comparisons to establish associations for classification. For example, sheep, goats and cattle have two toes on each foot and thus belong in the same taxonomic "box". Horses, having just a single toe on each foot, belong in a different "box". These authors never intended to imply that sheep, goats and cattle were more closely related to each other than they were to horses. It was Owen who first used the terms 'Artiodactyla' and 'Perissodactyla' in referring to the even-toed and odd-toed ungulates, respectively. One of the earliest and most comprehensive taxonomic classifications of mammals was published by Gray (1821) in which the ruminant families Moschidae, Giraffidae and Bovidae were first formally named.

The first true 'phylogenetic tree', one in which descent from common ancestors was implied, was drawn by Charles Darwin and published in Chapter IV of his Origin of Species (1859). Traditional taxonomic classification was almost immediately reconsidered with an evolutionary perspective. It is interesting to note that very little revision of the traditional taxonomic classification was required. The morphological traits upon which the taxonomies were based were essentially the same ones that were used to establish evolutionary relationships. Subsequently, more detailed analyses of both skeletal and soft tissue morphology were conducted. More recently, behavioral (Tinbergen, 1959; Lusseau, 2003) and embryological (Hall, 2000) characteristics have been considered in phylogenetic analyses. Such efforts have been augmented by the inclusion of more species and by increasingly rigorous evaluation of individual variation within species. Finally, mathematical methods for constructing phylogenies were developed and improved (Camin and Sokal, 1965; Felsenstein, 1985). Mammalian phylogenies underwent a period of regular revision, but eventually, a general consensus emerged. Simpson (1945) published a mammalian phylogeny that represents this consensus very well into the 1980s.

\section{What are ruminants?}

Ruminants are the most numerous group of extant ungulates (hoofed mammals). There are at least 250 recognized species of ruminant. The phylogenetic grouping Ruminantia is a suborder 
(McKenna and Bell, 1997) within the mammalian order Artiodactyla. Ruminants can be distinguished from other mammals by a few unique morphological characteristics. The cuboid and navicular bones in the tarsus are fused in all ruminants, including the oldest known fossil forms (ex. Dorcatherium; Milne-Edwards, 1864; Hypertragulus, Archaeomeryx and Gelocus; Webb and Taylor, 1980). Ruminants are one group among many groups of mammals that have compartmentalized stomachs to facilitate microbial digestion. However, ruminants can be distinguished from these other groups by two unique gross morphological characteristics of their compartmentalized stomach. The first is the structure of the first stomach compartment, the rumen. As in most mammals, the esophagus in artiodactyls joins the stomach along the lesser curvature. This leaves a blind sac at the 'anterior' end called the fundus. The rumen develops embryologically as an elongation of the fundic region. In ruminants, this elongated fundic 'sac' undergoes a unique, secondary folding into a Z-shaped pattern during development. The external surfaces of the developing 'rumen' fuse where they are brought into contact by the folding, creating the rumen's unique internal architecture (Hofmann, 1973; Langer, 1974; Stevens and Hume, 1995). It can be distinguished easily from the foregut structure of all other mammals, including other artiodactyl foregut fermenters, like camels, hippos and peccaries (Vallenas et al., 1971; Langer, 1975; Schwarm et al., 2010). Another unique structural feature is found in the second stomach compartment, the reticulum. The ruminants have a reticular network of ridges lining the inside surface of the reticulum (Hofmann, 1973). This is what gives the inside surface of the reticulum its characteristic "honeycomb" appearance. These features define ruminants to the exclusion of any other species.

The modern ruminants are divided into six families. The six families are presented in Table 1 along with three of the morphological characteristics that define them. The first characteristic is facio-cranial ornamentation, the presence of pronounced structures on the face or cranium that are used primarily in intraspecies competition for mates. These are typically sexually dimorphic, more highly developed in males, less developed or absent in females. In ruminants, tusks are well developed upper canines and are the only facial form of ornamentation. Cranial forms include horns, antlers and ossicones. Another distinguishing characteristic is the omasum, a compartment of the stomach that can sit between the reticulum and the last compartment, the abomasum. The omasum has 50-100 longitudinal folds of tissue suspended from the inner surface of its greater curvature. They lay parallel to each other creating a very effective filtering mechanism that greatly reduces the rate of passage of digesta into the abomasum. The last distinguishing characteristic in Table 1 is the form of placentation. The ruminant families differ in the form of placentation, based on the distribution of chorionic villi. These patterns of distribution can be diffuse or cotyledonary (associated with uterine caruncles). The cotyledonary form can be either oligocotyledonary in which there only 6-10 large uterine caruncles and associated cotyledons or polycotyledonary in which there are more than 50 small uterine caruncles and associated cotyledons.

Table 1. The families within Ruminantia and three of the morphological characteristics that help define them.

\begin{tabular}{lclll}
\hline FAMILY & Number of species & Facio-cranial ornamentation & Omasum & Placentation \\
\hline Tragulidae & 10 & tusks & no & diffuse \\
Moschidae & 7 & tusks & yes & oligocotyledonary \\
Cervidae & 90 & tusks or antlers & yes & oligocotyledonary \\
Giraffidae & 2 & ossicones & yes & polycotyledonary \\
Antilocapridae & 1 & horns (deciduous) & yes & polycotyledonary \\
Bovidae & 140 & horns (permanent) & yes & polycotyledonary \\
\hline
\end{tabular}


The Tragulidae (mouse-deer, chevrotains) separated from the rest of the ruminants about 35 million years ago (Bibi, 2013). Only ten species of tragulid survive today. Their geographic range is limited to tropical forests in Asia and Africa. They are the least derived of the six families. In other words, they have probably changed the least from the last ancestor common to all ruminants. Some consider tragulids to be 'living fossils' (Rössner, 2007). Among the ancestral characteristics maintained in tragulids are 1) tusks as opposed to cranial ornamentation (ossicones, horns or antlers), 2) the lack of an omasum and 3) a diffuse placentation. The remaining five families of ruminants are collectively referred to as the Pecora (McKenna and Bell, 1997) or pecoran ruminants. All pecorans have omasa. The Moschidae (musk deer) are among the least studied of the ruminant families. There are only seven known species of moschid. They are only found in temperate forests of Asia. They have retained tusks but are easily distinguishable from tragulids by having a well-developed omasum and being oligocotyledonary. The Cervidae are the true deer. There are about 90 species within the family Cervidae. They can be found in a variety of habitats (arctic to tropical) throughout Eurasia and the Americas. Most cervid species have antlers. Antlers are a unique form of cranial ornamentation. They consist of a dense, often branching, core of cartilaginous tissue that grows and gradually ossifies. During the growth phase, the antler is covered with skin (velvet). Once fully ossified, the skin is shed, leaving the completely ossified antler exposed. At the end of the breeding season, the antlers are shed. For this reason, antlers are often referred to as being 'deciduous'. A new set is grown each year (Davis et al., 2011). As a rule, the upper canines are absent in antlered cervids. There is one prominent group of cervids, the Chinese water deer (Hydropotes), that does not have antlers. They have well developed tusks instead. Just to complicate things further, elk (both the Eurasian (Cervus elaphus) and North American (Cervus canadensis) forms) have well developed antlers and also express small, upper canine 'tusks' in both sexes. Like the moschids, cervids have an omasum and an oligocotyledonary placentation. While many species of cervid are raised in captivity, reindeer are the only cervids that can be considered domesticated (Clutton-Brock, 1981). Due to their economic value (antler, meat, hide), there has been a fair amount of research done with cervids. Bovidae is the ruminant family with the greatest number of species. The family includes all of the Asian and African antelopes and gazelles. It also includes the truly domesticated ruminants: cattle, sheep, goats, water buffalo and yaks (Clutton-Brock, 1981). Bovids are found naturally in a wide range of habitats throughout Eurasia, North America and Africa. The domesticated forms have been distributed in large numbers to every part of the globe, including areas like South America, Australia, New Zealand where bovids never existed naturally. Owing to their large numbers and economic importance, the domesticated bovids are the most well studied ruminants. They are polycotyledonary and have true horns. In Bovidae, a horn consists of three parts, 1) a boney horn core, 2) a layer of specialized skin over the horn core and 3) a keratinized sheath covering the skin. The horn core grows continuously, throughout the animal's life. The keratinized sheath also grows to accommodate the core (Davis et al., 2011). The Giraffidae is a small family with only two extant species, the giraffe and okapi. They are geographically limited to the plains and forests of Africa, respectively. They are characterized by ossicones, a unique form of cranial ornamentation. Like horns, ossicones have a bony horn core that is covered with skin. Unlike horns, ossicones do not have a keratinized sheath (Davis et al., 2011). Giraffidae are polycotyledonary. The family Antilocapridae includes a single species, the pronghorn antelope of North America. The distinguishing feature for this family is the deciduous nature of its horn sheath. As in the Bovidae, the horn core grows throughout the animal's life. However, pronghorns shed the keratinized sheath each year as a new sheath is grown beneath to replace it (Davis et al., 2011). Like the giraffids, pronghorns are polycotyledonary. 


\section{Recent advances in mammalian phylogenetics that impact ruminants}

Over the last 30 years, mammalian phylogenetics has undergone some remarkable revisions. This has been due to the application of modern gene-sequencing technology, permitting the comparison of mRNA and DNA sequences among species. Two of the most intriguing revisions have occurred within the order Artiodactyla and have important implications for the ruminants. The first involves the relative position of the family Camelidae (camels and llamas). Camelidae had traditionally been considered sister taxon (the closest relatives) to the ruminants. This was based on highly-derived features shared by the two groups. These include the loss of upper incisor teeth, a compartmentalized stomach (three compartments in camelids), the reduction in the number of digits in each foot to two and the evolution of 'rumination' as an obligatory physiological process. A phylogenetic tree showing the popularly held view of relationships among families within the order Artiodactyla is shown in Figure 1. These relationships were widely accepted into the 1980s. Modern nucleotide sequencing data now clearly shows that the Camelidae was the earliest major branch to diverge from the stem artiodactyl group (Graur and Higgins, 1994; Gatesy, 1997; Gatesy et al., 1999; Shimamura et al., 1999; Spaulding et al., 2009). This divergence occurred about 60-65 million years ago (Bininda-Emonds et al., 2007; O'Leary and Gatesy, 2008; Hassanin et al., 2012). Despite

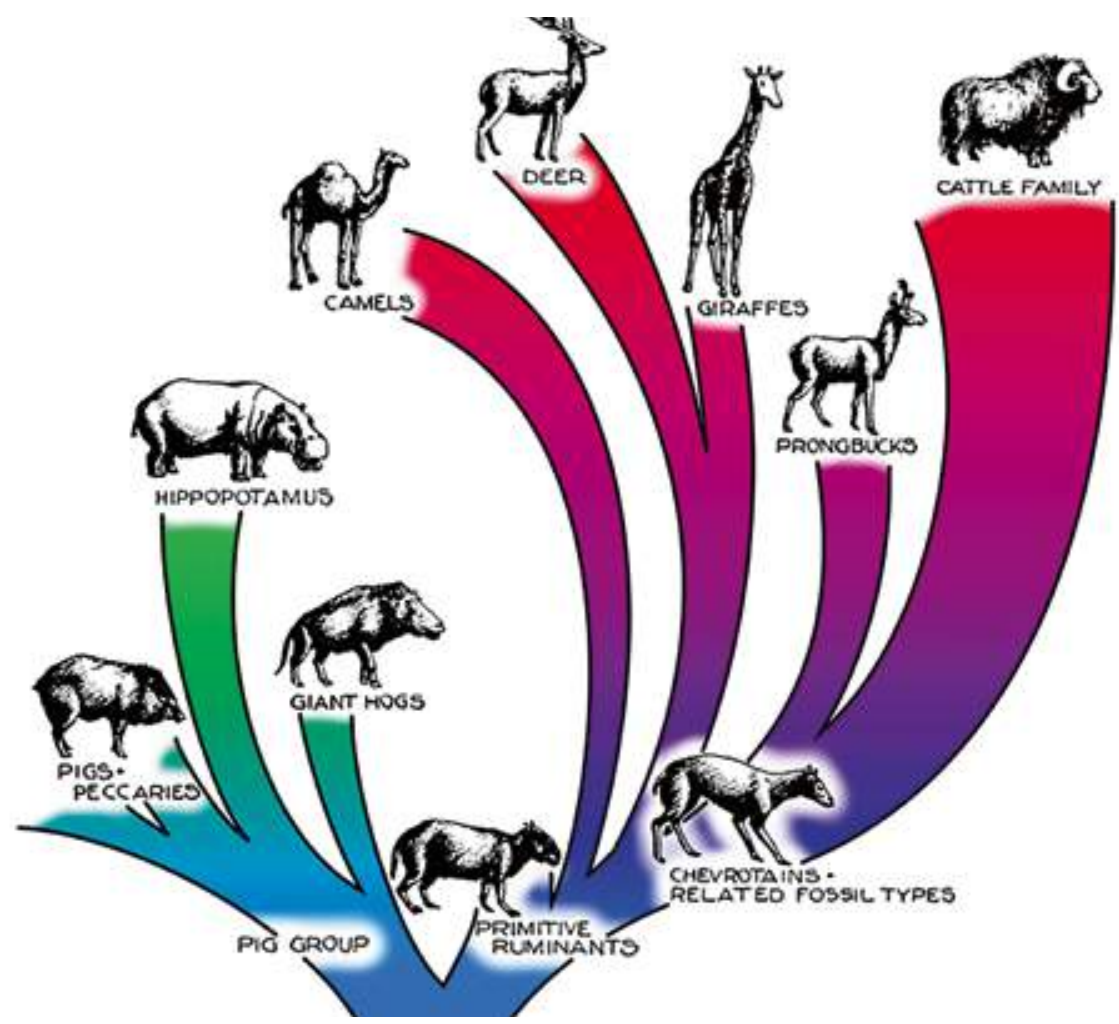

Figure 1: A family-level, phylogenetic tree of the Artiodactyla that is representative of the popular consensus circa 1930-1980 (Romer and Parsons, 1977).

Original caption: A family tree of the even-toed ungulates (artiodactyls). The major cleavage is into the pig group (left) and the cud-chewers, or ruminants (right). Among the latter, the camels appear to have diverged at an early date. 
their numerous morphological and behavioral similarities, it is now clear that ruminants and camelids are only very distantly related.

Until very recently, the Artiodactyla and the Cetacea (whales and dolphins) were considered to be separate orders within the class Mammalia. The relationship between these two orders has been radically revised. Based on nucleotide sequencing data, it is clear that the cetaceans are actually a group that is nested deeply within the Artiodactyla (Irwin and Arnason, 1994; Hasegawa and Adachi, 1996; Gatesy, 1997; Montgelard et al., 1997). Some refer to this combined order as Cetartiodactyla (Montgelard et al., 1997). Others, including myself, prefer to retain the traditional name Artiodactyla (Spaulding et al., 2009; Bibi 2013). Time will resolve this nomenclatural issue. Also based on nucleotide sequencing data, it has been recognized that the cetaceans and the hippos (family Hippopotamidae) are sister taxa (Irwin and Arnason, 1994; Hasegawa and Adachi, 1996; Gatesy, 1997; Montgelard et al., 1997). In some phylogenies, they are grouped together in a superfamily, Whippomorpha (Waddell et al., 1999) or Cetancodonta (Arnason et al., 2000). These data also indicate that the hippo/whale group is more closely related to the ruminants than to the other major artiodactyl families, the Suidae (pigs and hogs), Tayassuidae (peccaries) or the Camelidae. Based on this, a revised phylogenetic tree for the Artiodactyla is presented in Figure 2.

The close association of cetaceans and artiodactyls should come as no surprise to those of us who work with livestock. First, a compartmentalized stomach is extremely rare in most mammalian

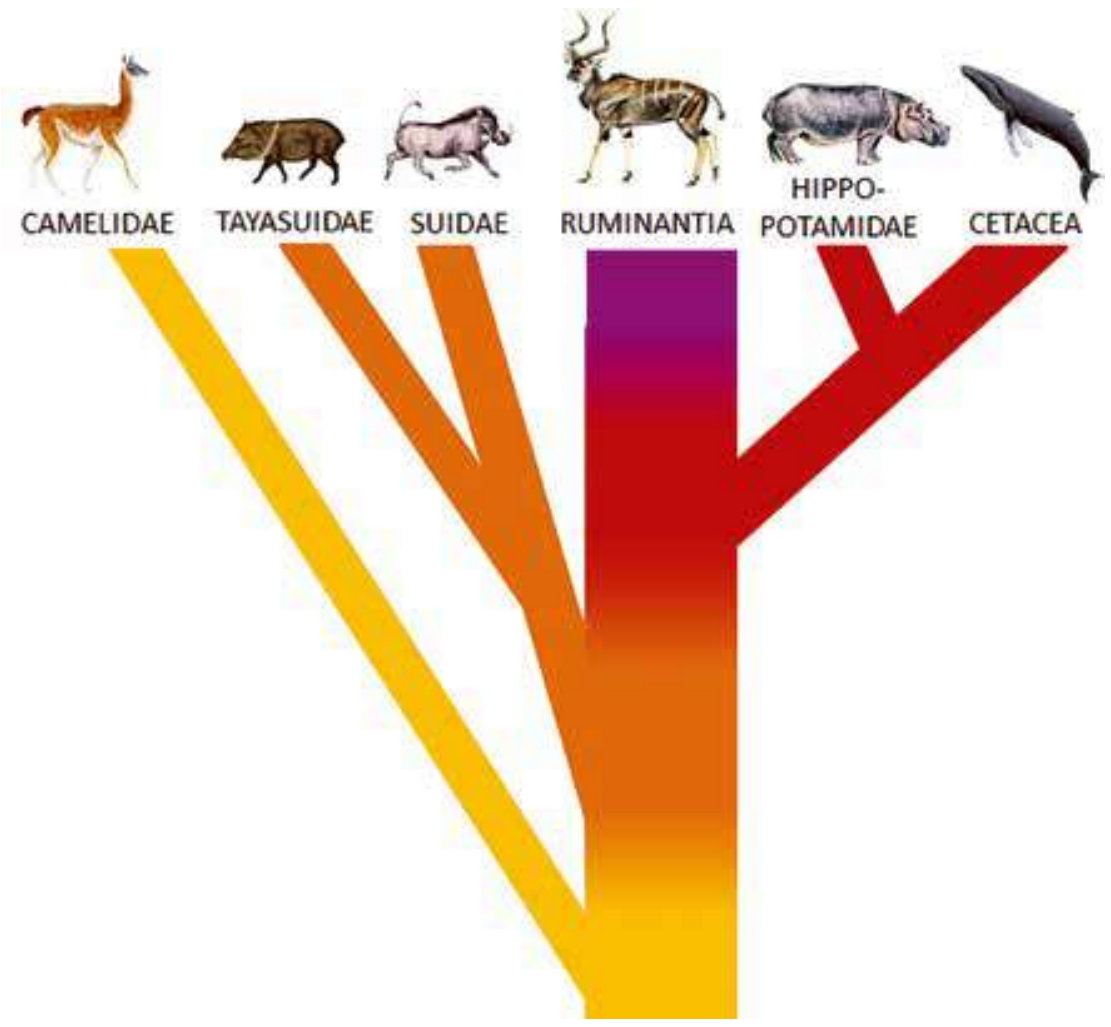

Figure 2. A revised phylogenetic tree for the Artiodactyla based on molecular data, representing the modern consensus as described in the text. Note that the families within Ruminantia are not separated in this 'tree'. Species icon references: Camelidae and Cetacea (Canevari and Vaccaro, 2007); Tayassuidae (Reid, 2006); Suidae and Ruminantia (Kingdon, 1997); Hippopotamidae (Dorst and Dandelot, 1972). 
orders but a very common feature throughout the Artiodactyla. It is found in ruminants, hippos, camelids and tayasuids (Langer, 1974; Stevens and Hume, 1995; Schwarm et al., 2010). The only other mammalian order with such an abundance of species possessing compartmentalized stomachs is the Cetacea (Harrison et al., 1970; Herwig et al., 1984; Herwig and Staley, 1986; Olsen and Mathiesen, 1996; Mead, 2007). Second, like artiodactyls, the cetaceans also have an epitheliochorial type of placentation (Mossman, 1987). Third, male artiodactyls have a fibroelastic penis with a distinctive sigmoid flexure (S-shaped bend). Cetacea is the only other mammalian order in which this unique penis structure is found (Slijper, 1966; Bland and Kitchener, 2001).

While still a contentious issue among some morphologists, most researchers in the field accept that molecular-based phylogenies will prove to be correct. In the vast majority of cases where morphology and gene sequence-based phylogenies differed, the sequence-based phylogenies have eventually been shown to be the most accurate. The few exceptions have been ones where an inadequate number of species or sequences were sampled. These were then found to be incorrect based on more extensive sequencing. At this point in time, the ruminants have been examined extensively and many aspects of their phylogeny are well defined. The phylogenetic relationships among the ruminant families are depicted in Figure 3. Obviously, some important

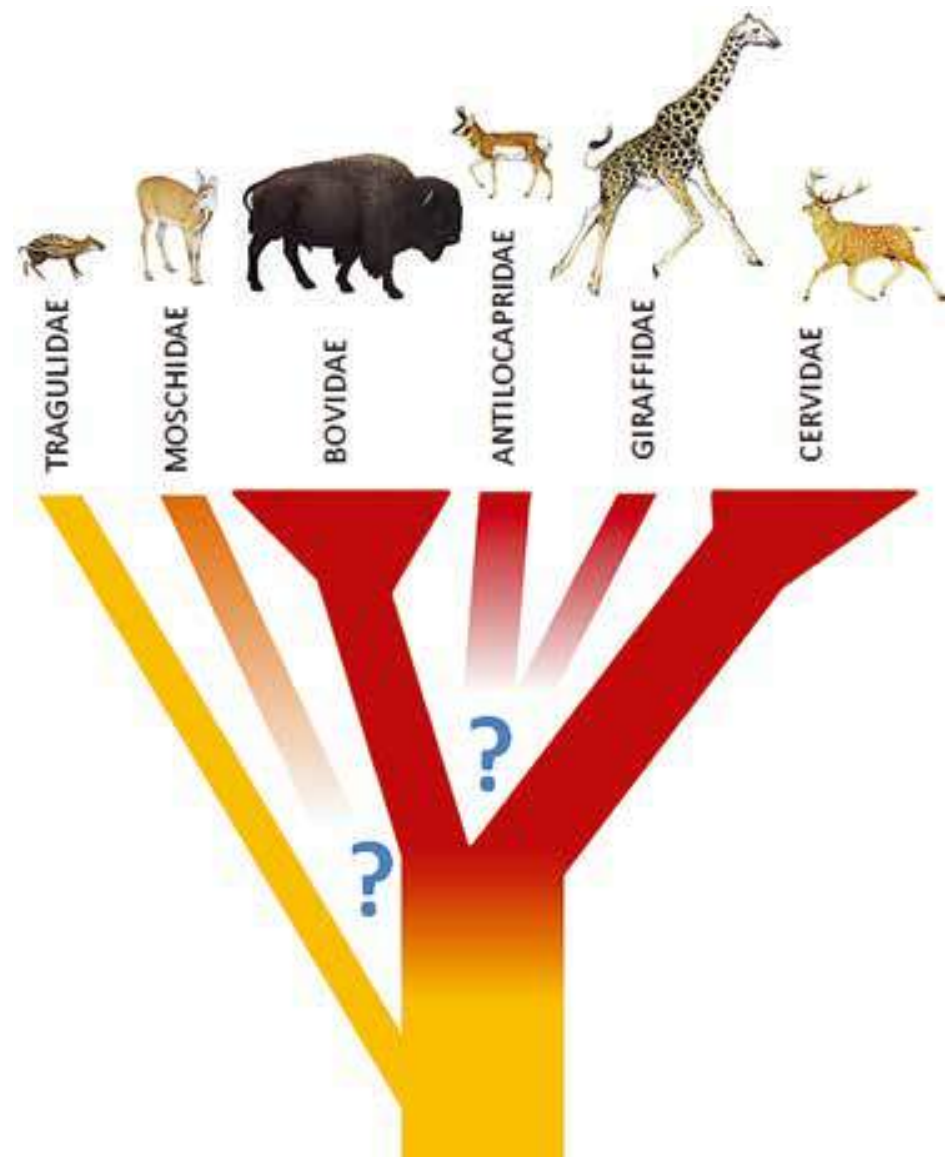

Figure 3. A revised phylogenetic tree for the Ruminantia based on molecular data, representing the modern consensus as described in the text. Species icon references: Tragulidae, Cervidae and Giraffidae (Kingdon, 1997); Moschidae (Monde des Mammiferes, 2013); Antilocapridae (Reid, 2006); Bovidae (Burt and Grossenheider, 1976). 
relationships remain unresolved. As described in the second section, the Tragulidae are an ancient family separating from the rest of the ruminants 30-35 million years ago . Precise phylogenetic relationships among the remaining five ruminant families have not been resolved. This is due, in large part, to the small numbers of extant species left in many of the remaining families. There is no doubt that all five of these families diverge from each other between 17 and 25 million years ago (Bibi, 2013). The problem is in defining the precise pattern and order. Recent studies, with larger data sets, place the Giraffidae and Antilocapridae as early offshoots from the ruminant tree (Decker et al., 2009; Spaulding et al., 2009; Hassanin et al., 2012; Bibi, 2013). The Moschidae are consistently found to be closer to the Bovidae than to the Cervidae. Within families, most phylogenetic relationships are well defined. This is particularly true for the families with 10 or fewer extant species. Within the more numerous Bovidae and Cervidae, some phylogenetic relationships have yet to be resolved.

Before describing the phylogenetic relationships within specific ruminant families in detail, it is important to address how phylogenetic trees are determined. This is explained briefly

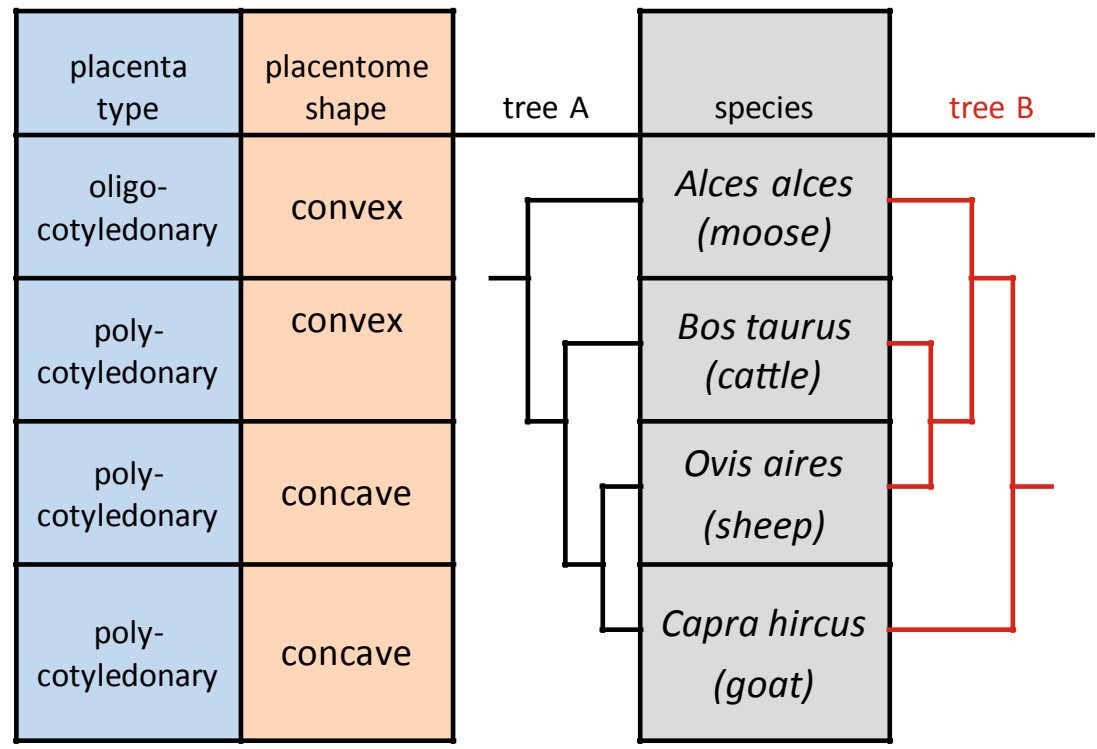

Figure 4. Building a phylogenetic tree. A phylogenetic tree is an attempt to depict the simplest set of evolutionary relationships that can explain the distribution of a set of characteristics among a group of species. Phylogenetic trees can be generated using a variety of different mathematical approaches. Each of these methods attempts to find the tree that minimizes transitions from one character state to another. The assumption is that specific evolutionary changes are rare, unlikely to repeat themselves and very unlikely to reverse themselves. For comparisons involving morphological characteristics, reversals are almost impossible. For comparisons involving nucleotide sequences, reversals are certainly rare but possible. In the very simple example shown here, we have four species and just two placental characteristics. Assume that the oligocotyledonary condition is the ancestral (starting) condition. The polycotyledonary condition only has to 'evolve' once, in a common ancestor to cattle, sheep and goats. Assume that the convex shape is ancestral. The concave placentome only has to 'evolve once', in a common ancestor to the sheep and goat. Any other tree will require more transitions. Tree B is an alternative. Once again, assume that the oligocotyledonary condition is ancestral, then the polycotyledonary condition evolved independently, at least twice, in the line leading to the goat and again in a common ancestor to sheep and cattle. Likewise, if the convex placentome is ancestral, the concave placentome evolved twice, in the line leading to goats and again in the line leading to sheep. Thus, tree B is a much more complicated explanation for how these characteristics evolved than tree A. While tree B is certainly a possible explanation and may actually be true, tree $\mathrm{A}$ is much simpler and much more likely to be true. 
in Figure 4. It is also important to understand how to interpret the information presented in trees and to evaluate their accuracy. This is described in Figure 5. The major phylogenetic relationships within the Bovidae are presented in Figure 6. Bovidae are traditionally separated into eleven 'tribes'. Species from two of these tribes (Caprini and Bovini) have been successfully domesticated. There are about 35 species in the Caprini. A phylogeny for a representative group of these is presented in Figure 7. Domestic sheep and goats are both members of the Caprini. A proposed phylogeny for the Bovini is presented in Figure 8. Domesticated members

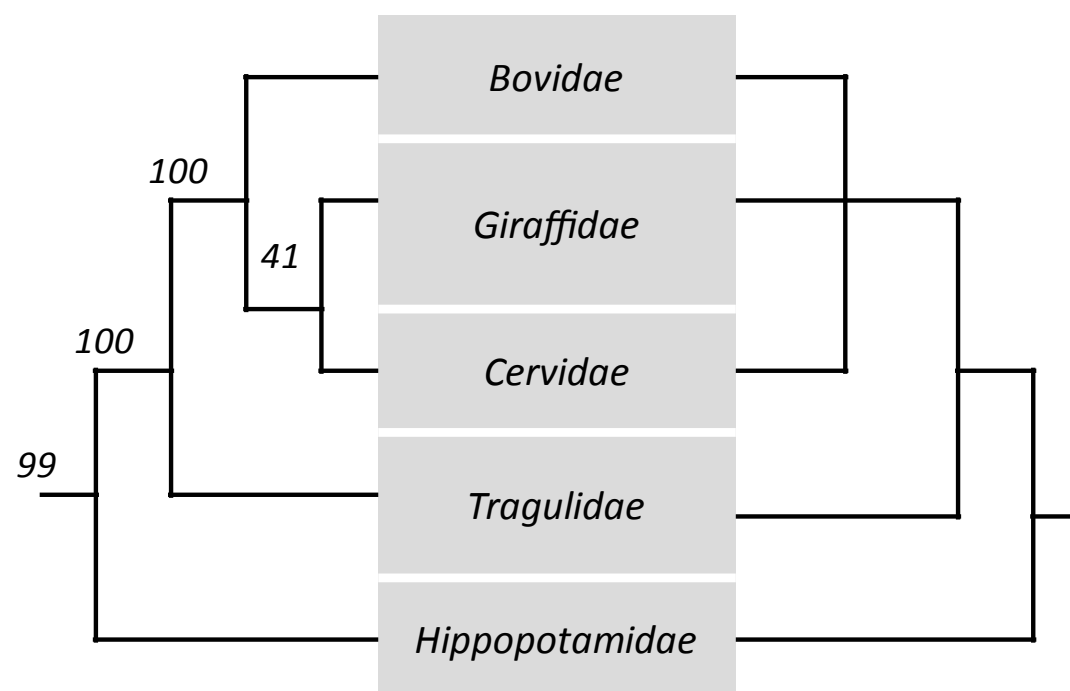

Figure 5. Reading and evaluating a phylogenetic tree. This is a portion of the phylogenetic tree presented by Gatesy (1997). It shows the phylogenetic relationship among four families within Ruminantia and the Hippopotamidae. In the orientation used here, it may be simplest to move backwards in the evolutionary sense (to the left), from the individual species. The phylogenetic tree indicates that the ruminant families Giraffidae and Cervidae are more closely related to each other than to any other families in the analysis. In some trees, the length of the horizontal lines leading to the junction point is representative of the number of character differences between the groups (or species). Keep in mind that we are moving in evolutionary 'reverse'. If we were to follow the evolutionary path, the 'junction point' is really a divergence point, where groups separate. In many trees, a numerical value (0-100) can be found at the junction points. These are bootstrap values. These are estimates of how reliable the association between these groups is. Bootstrap values are generated by rerunning the tree forming algorithm using a subset of the starting data set in which only some of the characteristics, chosen at random, are used. These tests are usually done 500-2000 times. The bootstrap value is the \% of these trees in which this relationship is supported. In this case, the bootstrap value is $41 \%$. This is very low. Most phylogeneticists use $80 \%$ bootstrap support as a cut off for a supported relationship. Thus, we have little support for the association between Cervidae and Giraffidae. Alternative associations (Bovidae-Giraffidae, Bovidae-Cervidae) are very possible. Presentation of this relationship in a tree can take two forms. The weakly supported relationship is depicted on the left. The alternative is to present the unresolved relationship as on the right, as several lines coming together at a single junction point or level. This implies that the specific relationships among groups at this level have not been resolved. The relationships are much clearer at subsequent levels. Continuing to the left, the bootstrap value for the group of Bovidae-Giraffidae-Cervidae is $100 \%$, indicating that this group of three consistently clusters in every tree. Likewise, the association with the Tragulidae consistently occurs at the next level. The last family included in this tree is Hippopotamidae, an outgroup. Every phylogenetic tree should include at least one outgroup for comparison. An ideal outgroup is phylogenetically close to, but clearly outside of, the group being analyzed. In this case, Hippopotamidae is an artiodactyl, but not from the suborder Ruminantia. It is less constructive or informative to use very distantly related species as outgroups (ex. canids, primates, birds) as these rarely challenge the characteristic data set on which the group is being evaluated. 


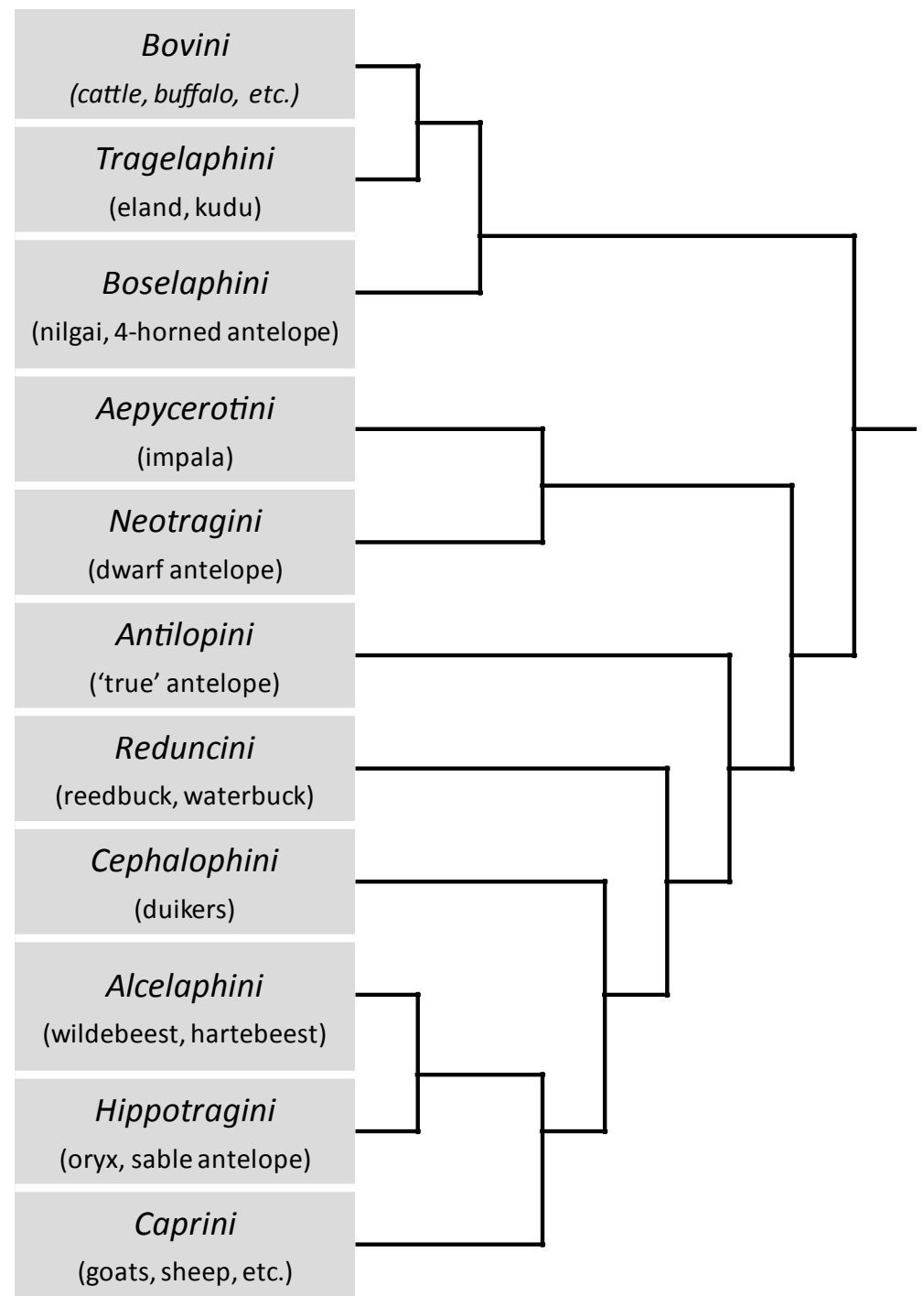

Figure 6. A phylogeny for the family Bovidae (Hassanin et al., 2012).

of the Bovini include cattle (both subspecies of Bos taurus), yaks, water buffalo (both species), mithan and banteng. The true buffalo (i.e. water buffalo, genus Bubalus, and cape buffalo, genus Syncerus) form a distinct group whose ancestors diverged relatively early (about 11 million years ago) from the rest of the Bovini. The more cold-adapted Bovini (bison and yaks) consistently form a group in phylogenetic studies (references in Figure 8). The more tropically adapted Bovini (gaur, mithan, banteng and kouprey) consistently form another group. However, studies differ in the placement of cattle (Bos taurus). In some, cattle are more closely associated with the tropical group. In others, cattle are more closely related to the cold-adapted Bovini. However, the reliability of these particular relationships is consistently low in all of these studies. Resolving the phylogenetic position of cattle will continue to be one of the highest research priorities in this field. A phylogeny for some representative Cervidae is presented in Figure 9. Although reindeer are the only cervids that can be considered domesticated, many others have 


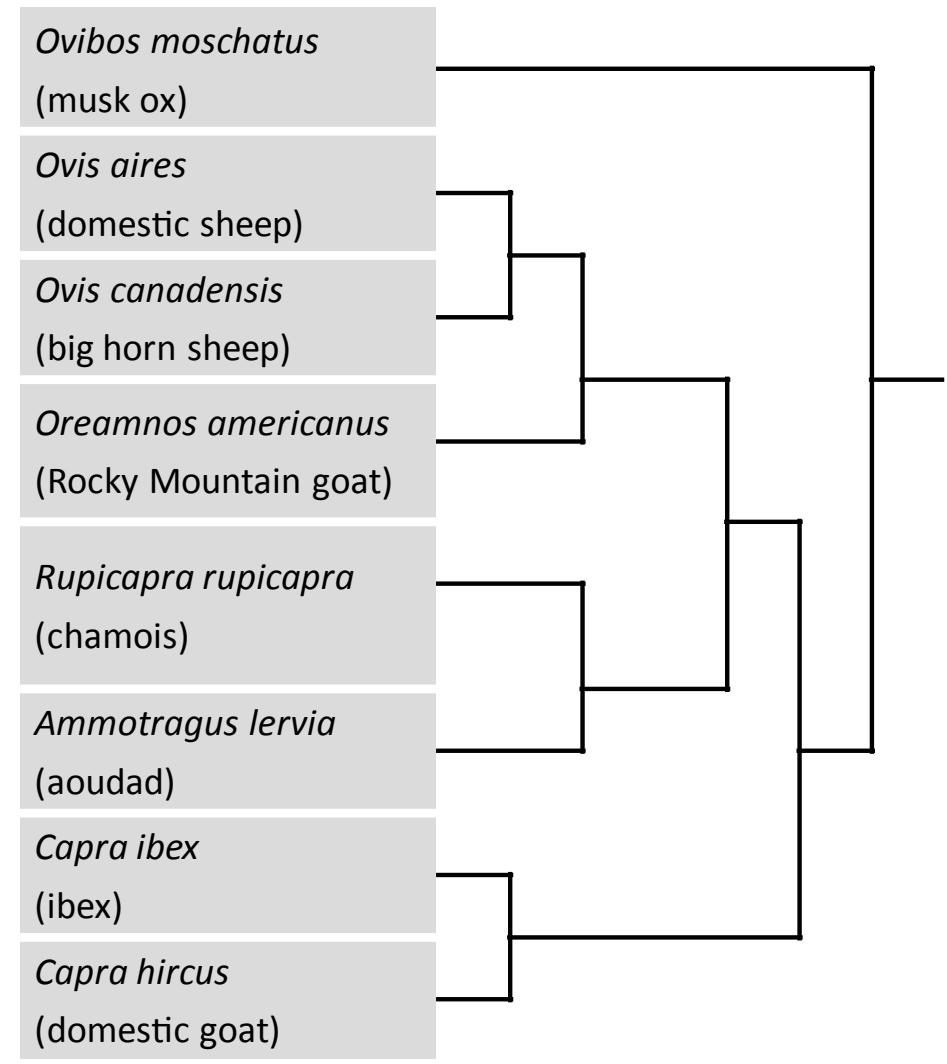

Figure 7. A phylogeny of eight representative species from the bovid tribe Caprini. This phylogeny includes musk oxen, sheep and goats. Phylogenetic relationships are based on Jiang et al. (2013).

economic importance and are either herded or raised in confinement. These include wapiti, red deer and white-tailed deer. The major phylogenetic relationships within the Cervidae are well resolved. There is a major division separating the subfamilies Capreolinae and Cervinae. This separation was first proposed based on a major difference in the pattern of metacarpal reduction between the two groups (Brooke, 1878). Gene sequencing confirmed the separation. The Capreolinae include the roe deer, white-tailed deer, mule deer, moose, reindeer, all native South American deer and the aforementioned, antlerless, Chinese water deer. The Cervinae include wapiti, red deer, axis deer, fallow deer, muntjacs and many others.

\section{Using reproductive characteristics to resolve phylogenetic controversies}

As noted above, I am confident that the most accurate phylogeny for any group of mammals will ultimately be revealed through gene sequencing. That being said, some phylogenetic relationships have been difficult to resolve at the level of sequencing currently used, i.e. mitochondrial and nuclear genes, mRNAs, SINEs, SNPs, etc. More and more sequences are being added but we are still only comparing a small fraction of the total genome. It is very possible/ likely that important, informative sequences are being missed. This is particularly concerning 


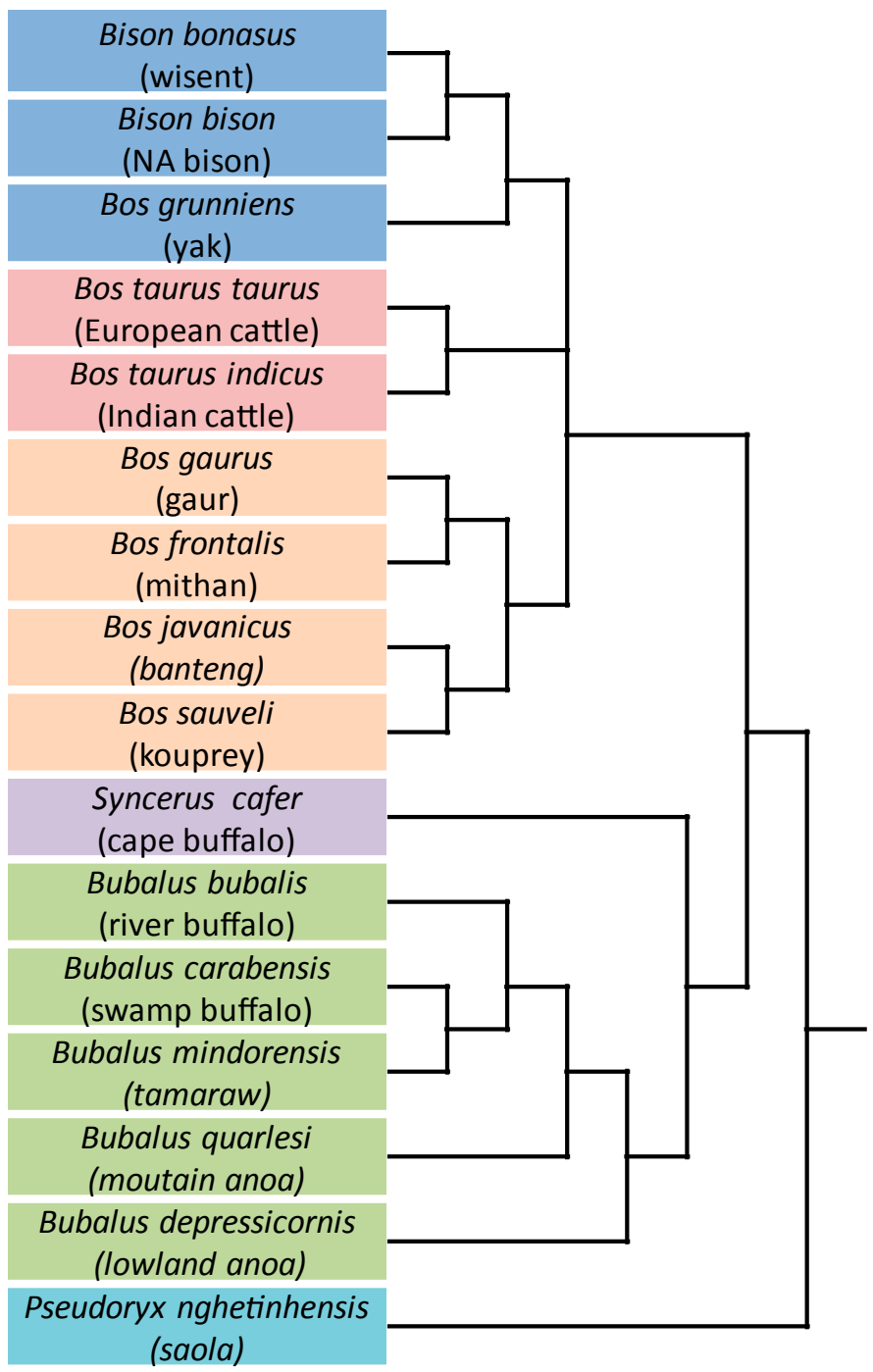

Figure 8. A phylogenetic tree for the bovid tribe Bovini. This phylogeny includes 15 species. The two subspecies of Bos taurus are included as separate taxa (shaded in pink). Note the inability to precisely place Bos taurus. Relationships between Bos taurus, the cold-adapted Bovini (bison and yak; shaded in blue) and the tropically adapted Bovini (gaur, mithan, banteng and kouprey; often given the subgenus designation Bibos; shaded in orange) are based on nuclear (primarily autosomal) gene sequences to avoid issues associated with introgression of maternal or paternal DNA markers due to hybridization. This portion of the tree is based on the following references: Buntjer et al., 2002; Verkaar et al., 2004; Hassanin and Ropiquet, 2007; MacEachern et al., 2009a;b; Hassanin et al., 2013. More extensive research is needed to reconcile the placement of Bos taurus. Placement of Bubalus species (shaded in green) is based on mitochondrial cytochrome $b$ gene sequences (Tanaka et al., 1996). Placement of the saola is based on Hassanin et al. (2013).

when only a few species exist to represent a whole family. In such cases, genomic differences associated with individual species may be misinterpreted as characteristics of the family. It may be many years before we are in a position to conduct complete genome sequencing on an adequate number of ruminants to resolve these relationships. Besides, we are in the earliest 


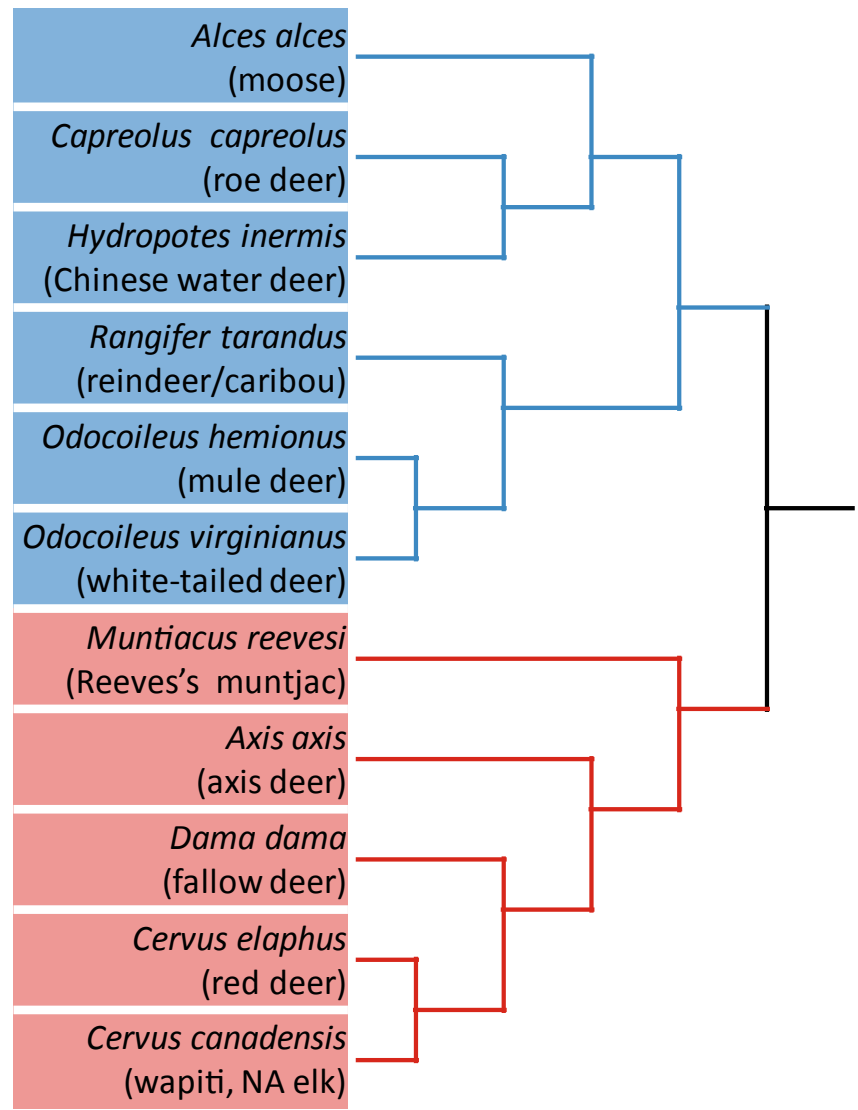

Figure 9. A phylogeny of eleven representative species from the Cervidae (Hassanin et al., 2012). Members of the subfamily Capreolinae are indicated in blue. Members of the subfamily Cervinae are indicated in red.

stages of developing methodologies for comparing whole genomes. We have only a very crude understanding of how the genome is organized, the role of 'noncoding' DNA, etc. Until these issues are resolved, we must be content to add more sequences and use other forms of data to supplement the sequencing. Integrating sequence, morphological and behavioral data into a useful 'data set' is a challenge. Of course, this is the only way most extinct species can be incorporated into a phylogenetic analysis. This kind of approach has been used to study the earliest radiation of placental mammals, where inclusion of fossil data is essential ( $\mathrm{O}^{\prime}$ Leary et al., 2013). It has also been used to study phylogenetic relationships within the ruminants (Hernandez Fernadez and Vrba, 2005; Spaulding et al., 2009). Reproductive characteristics of existing species may be particularly useful in these types of analyses. There is tremendous variation in the reproductive anatomy, physiology and behavior among mammals, especially when compared to other anatomical structures and physiological processes. There are sound biological reasons for this as will be discussed later. I'd like to consider a few examples of how reproductive characteristics can be used to assist in phylogenetic analyses.

One possibility is to perform focused sequencing on genes associated with reproduction. An example that might serve to illustrate this point is the trophoblast Kunitz-domain proteins (TKDPs) expressed in the placentae of cattle and sheep. The TKDPs are an example of a gene 


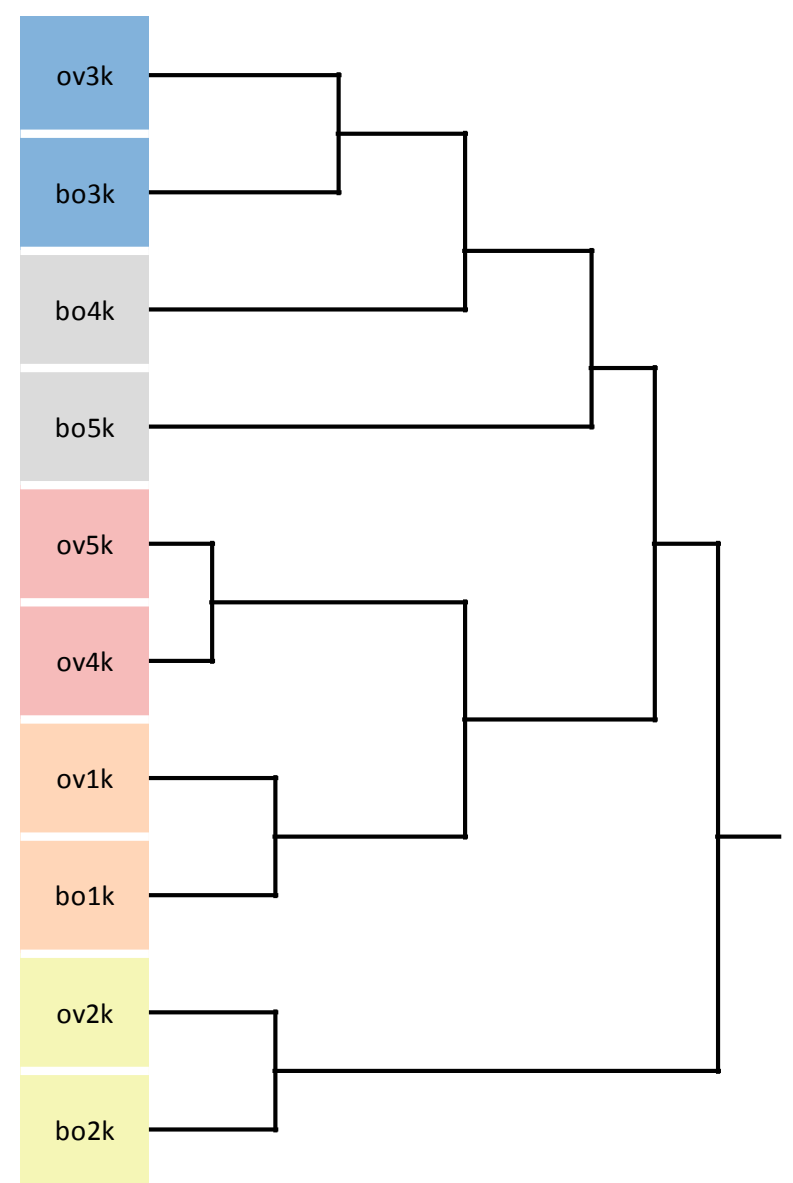

Figure 10. A phylogenetic tree for the bovine and ovine trophoblast Kunitz domain protein (TKDP) gene family (Chakrabarty et al., 2006).

family, a set of genes with similar sequences that arose from the successive replications of an original starting form. These genes are frequently found adjacent to each other in the genome. There are at least five TKDPs in both cattle and sheep, the only species in which the TKDPs have been described to date (Chakrabarty et al., 2006). The 'phylogenetic' relationship between the Kunitz-domain sequences in cattle and sheep TKDP genes is shown in Figure 10. Three of the bovine sequences have corresponding 'orthologs' in sheep. These are designated bo1k, bo $2 \mathrm{k}$ and bo3k in cattle and ov $1 \mathrm{k}$, ov $2 \mathrm{k}$ and ov $3 \mathrm{k}$ in sheep. The other two sequences are quite different. The paralogous sheep sequences (ov $4 \mathrm{k}$ and ov $5 \mathrm{k}$ ) are considerably longer and more similar to each other than to any bovine TKDP. They appear to have arisen by duplication from an ov $1 \mathrm{k}$-like ancestral gene. The appearance of paralogs, ov $4 \mathrm{k}$ and ov $5 \mathrm{k}$ probably occurred after the divergence of the sheep and cattle lineages. One of the unmatched bovine sequences (bo4k) is most similar to the bo3K and ov3K orthologs and likely arose through duplication of bo3k. The other (bo5k) is a unique, truncated form, also arising from the bo3k-bo4k group. From this very simple example, one can see that there is a set of TKDPs that may link all Bovidae (k1, k2 and $\mathrm{k} 3$ forms) and other TKDPs that may be specific to the Bovini and Caprini tribes. How can this information be used to assist with phylogenetic comparisons? Obviously, the sequence data itself can be added to the other sequences already being used for sequence comparisons. 
However, a gene family offers another avenue for phylogenetic comparisons. You can ask a series of simple yes/no questions. Does species $X$ have an ortholog that corresponds to bo1k? Does species $X$ have an ortholog that corresponds to bo2k? How are specific orthologs arranged in the genome relative to each other? This can be done for all known unique sequences and will generate a matrix of binary characters, similar to ones used in traditional morphological phylogenetic comparisons. A much more comprehensive examination of TKDPs in many more ruminants will be required to determine if there is any utility in this approach. For example, it would be interesting to characterize TKDPs in the Bovini to see if it can help resolve the phylogenetic placement of Bos taurus. If and when specific patterns of TKDP gene organization are known for Bovidae and Cervidae, TKDP gene family comparisons may be added to the 'data base' to properly place the Giraffidae, Antilocapridae and Moschidae. There are three other placentally-expressed, gene families that may offer similar phylogenetic opportunities in ruminants, interferons- $\tau$ (Walker and Roberts, 2009), prolactin-related proteins (Ushizawa and Hashizume, 2006; Ushizawa et al., 2007) and pregnancy-associated glycoproteins (PAGs; Telugu et al., 2009).

Another way to assess phylogenetic relationships may be to look at something as simple as survival of interspecies embryo transfers. We may be able to use this type of data to help resolve the phylogenetic placement of Bos taurus within the Bovini. Bos taurus indicus embryos have been transferred to Bos taurus taurus cows. Pregnancy was established and proceeded to term (Summers et al., 1983). Bos gaurus embryos have been transferred to Bos taurus cows and also carried to term (Stover et al., 1981). Bison bison embryos have been transferred to Bos taurus recipients. Again, pregnancy is established but is terminated sometime between 60 and 100 days of gestation (Dorn, 1995). If Bubalus bubalis embryos are transferred to Bos taurus cows, pregnancy is established but is terminated by 38 days (Drost et al., 1986). It appears that the duration of survival of the transplanted embryo may be related to the phylogenetic relationship between the embryo and the recipient. Clearly, Bos taurus taurus and Bos taurus indicus are very closely related, now considered by many to be subspecies within Bos taurus rather than separate species (Bradley et al., 1996; Buntjer et al., 2002; Hassanin et al., 2013). As expected, embryos from one subspecies survive to term in the other. At the other extreme, the most distant relationship investigated is between Bubalus bubalis and Bos taurus. Pregnancies survived less than 40 days in this situation. The other two transfers may be phylogenetically informative. Gaurs (Bos gaurus) are members of the tropical-adapted group within the Bovini. Gaur embryos can be carried to term in Bos taurus cows. Bison (Bison bison) are members of the cold-adapted group within the Bovini. Bison embryos survive 60-100 days in Bos taurus cows. This simple analysis suggests that cattle are more closely related to the tropically adapted Bovini than to the cold-adapted Bovini. Obviously, it is premature to make such a suggestion with so little data available. Ideally, one would like to see embryos from other species in the tropical-and cold-adapted groups transferred to Bos taurus cows. It is also important to include the reciprocal transfers of Bos taurus embryos to the other species. Ultimately, one would like to see a complete set of interspecies embryo transfers conducted within the Bovini as defined in the matrix shown in Table 2.

A third example of how reproductive biological data might contribute to resolving phylogenetic questions within the ruminants is the use of behavioral characteristics. Cap et al. (2008) identified 18 characteristics of male vocal behavior in 11 species of deer. The majority of these vocalization characteristics were related to reproduction: male-male confrontation, malefemale mating call, male-female courtship dialogue, etc. They compared the phylogeny derived from the analyses of the behavioral data to the phylogeny generated from 2 mitochondrial and 2 nuclear gene sequences from the same 11 species. Both phylogenies are presented in 
Table 2. Results of Interspecies Embryo Transfer in the Bovini

\begin{tabular}{|c|c|c|c|c|c|c|c|c|c|c|c|c|c|}
\hline \multicolumn{14}{|c|}{ Donor Species (embryo) } \\
\hline \multicolumn{2}{|c|}{ Common name } & 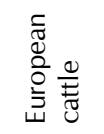 & 兽 & $\begin{array}{l}\overline{\bar{\Xi}} \\
\text { 离 }\end{array}$ & $\frac{\frac{c}{\widetilde{E}}}{\stackrel{t}{E}}$ & 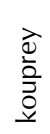 & 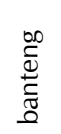 & $\frac{\ddot{\pi}}{\lambda}$ & 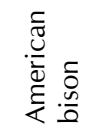 & 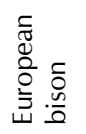 & $\sum_{\frac{\Phi}{\alpha}}^{\frac{0}{\pi}} \frac{0}{5}$ & 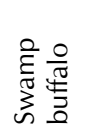 & ق \\
\hline \multicolumn{2}{|c|}{$\begin{array}{l}\text { Binomial } \\
\text { classification }\end{array}$} & 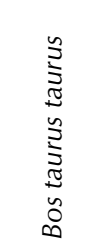 & 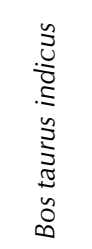 & 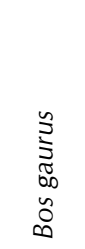 & 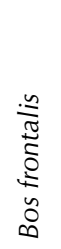 & $\begin{array}{l}\overline{\overline{0}} \\
\sum_{\tilde{D}} \\
\tilde{D} \\
\tilde{D} \\
\infty\end{array}$ & 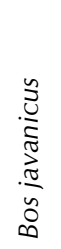 & 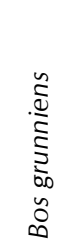 & 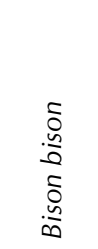 & 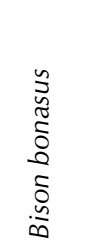 & 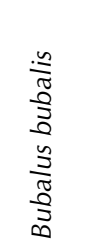 & 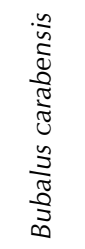 & 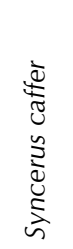 \\
\hline \multirow{12}{*}{ 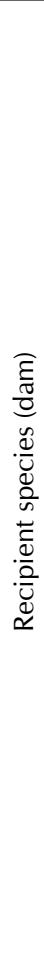 } & $\begin{array}{l}\text { Bos taurus } \\
\text { taurus }\end{array}$ & Term* & Term & Term & & & & & $\begin{array}{c}\text { 60-100 } \\
\text { days }\end{array}$ & & $\begin{array}{c}38 \\
\text { days }\end{array}$ & & \\
\hline & $\begin{array}{l}\text { Bos taurus } \\
\text { indicus }\end{array}$ & Term & Term & & & & & & & & & & \\
\hline & $\begin{array}{l}\text { Bos } \\
\text { gaurus }\end{array}$ & & & & & & & & & & & & \\
\hline & $\begin{array}{l}\text { Bos } \\
\text { frontalis }\end{array}$ & & & & & & & & & & & & \\
\hline & $\begin{array}{l}\text { Bos } \\
\text { sauveli }\end{array}$ & & & & & & & & & & & & \\
\hline & $\begin{array}{l}\text { Bos } \\
\text { javanicus }\end{array}$ & & & & & & & & & & & & \\
\hline & $\begin{array}{l}\text { Bos } \\
\text { grunniens }\end{array}$ & & & & & & & Term & & & & & \\
\hline & $\begin{array}{l}\text { Bison } \\
\text { bison }\end{array}$ & & & & & & & & Term & & & & \\
\hline & $\begin{array}{l}\text { Bison } \\
\text { bonasus }\end{array}$ & & & & & & & & & & & & \\
\hline & $\begin{array}{l}\text { Bubalus } \\
\text { bubalis }\end{array}$ & & & & & & & & & & Term & & \\
\hline & $\begin{array}{l}\text { Bubalus } \\
\text { carabensis }\end{array}$ & & & & & & & & & & & Term & \\
\hline & $\begin{array}{l}\text { Syncerus } \\
\text { caffer }\end{array}$ & & & & & & & & & & & & \\
\hline
\end{tabular}

*Term: pregnancy carried to term

Figure 11. For the most part, the two approaches gave very similar results. There were some differences in how four species and subspecies of Cervus separate themselves. The biggest and most concerning difference between the behavioral phylogeny of Cap et al. (2008) and a more generally accepted, sequence- based phylogeny like the one of Hassanin et al. (2012) presented in Figure 9 is the failure to accurately resolve the Cervinae and Capreolinae lineages. It is important to note here that the sequence-based phylogeny presented by Cap et al. (2008) was based on the same 11 species and was not able to resolve this important phylogenetic pattern either (Figure 11). This may simply be a problem with the number of characteristics and the number of species examined. The phylogeny presented by Hassanin et al., (2012) was based on a much more thorough evaluation of the mitochondrial genome and included 18 


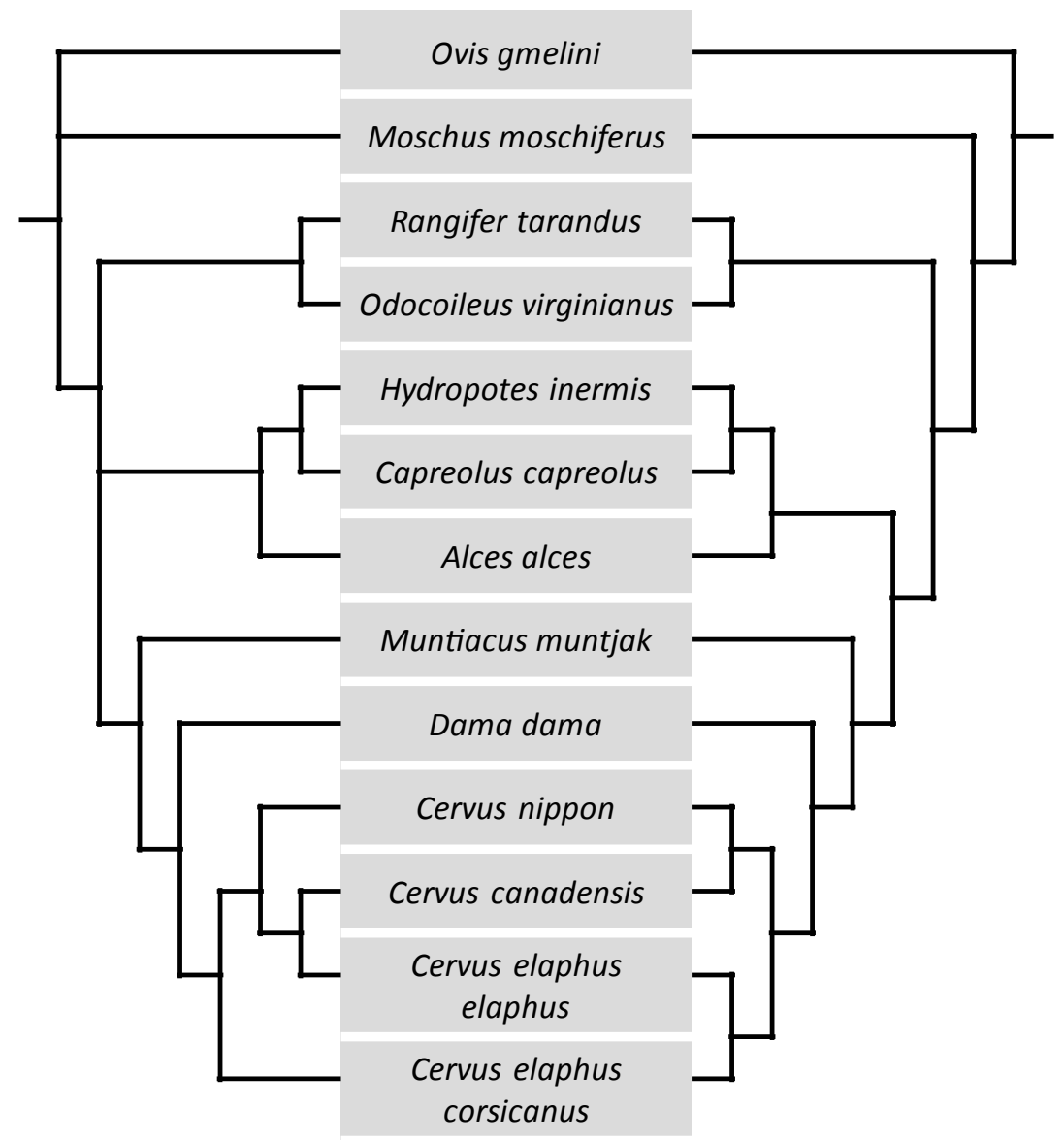

Figure 11. Phylogenetic trees for eleven species of Cervidae based on nucleotide sequences (left) and on male vocalization characteristics (right) (Cap et al., 2008).

species of Capeolinae and 20 species of Cervinae. Despite the obvious problem shown here, I believe that behavioral characteristics can be helpful in resolving some phylogenetic questions. It is important to recognize how often the two approaches agreed. Cap et al. (2008) describe the difficulties in identifying phylogenetically useful characteristics. As our understanding of behavior improves, our ability to use it in phylogenetic analyses will improve.

\section{How can the knowledge of ruminant phylogenetics be used to benefit reproductive research?}

Understanding the phylogenetic relationships among ruminants has many useful applications in reproductive research. One obvious way that phylogenetics can be applied to reproductive research is in the development of procedures to improve reproductive performance of understudied species. Suppose you wanted to develop a superovulation procedure for muskoxen. Your first inclination may be to try protocols based on previous work done in cattle. However, muskoxen are members of the Caprini. A more successful protocol may be developed sooner if one started with protocols developed in sheep and goats. 
Another interesting application is to take an accepted phylogenetic tree and examine how specific reproductive characteristics are expressed in the context of the tree. Using this approach, one can study how a characteristic evolved over time within lineages. Klisch and Mess (2007) used this approach to study the evolutionary development of the epitheliochorial placenta in Artiodactyla. They used a published, sequence-based phylogeny (Price et al., 2005) as a starting point. They assembled a data set of eight placental characteristics based on published reports. They included 12 species of ruminants, 3 cetaceans, 2 suids, 2 camelids and hippos. Characteristics included the number and shape of placentomes, presence of trophoblast giant cells, branching patterns of chorionic villi, etc. Using this approach, they were able to demonstrate clear patterns of development for some placental characteristics. A good example is placentome number (Figure 12). The initial or ancestral condition is to have a diffuse placenta with no

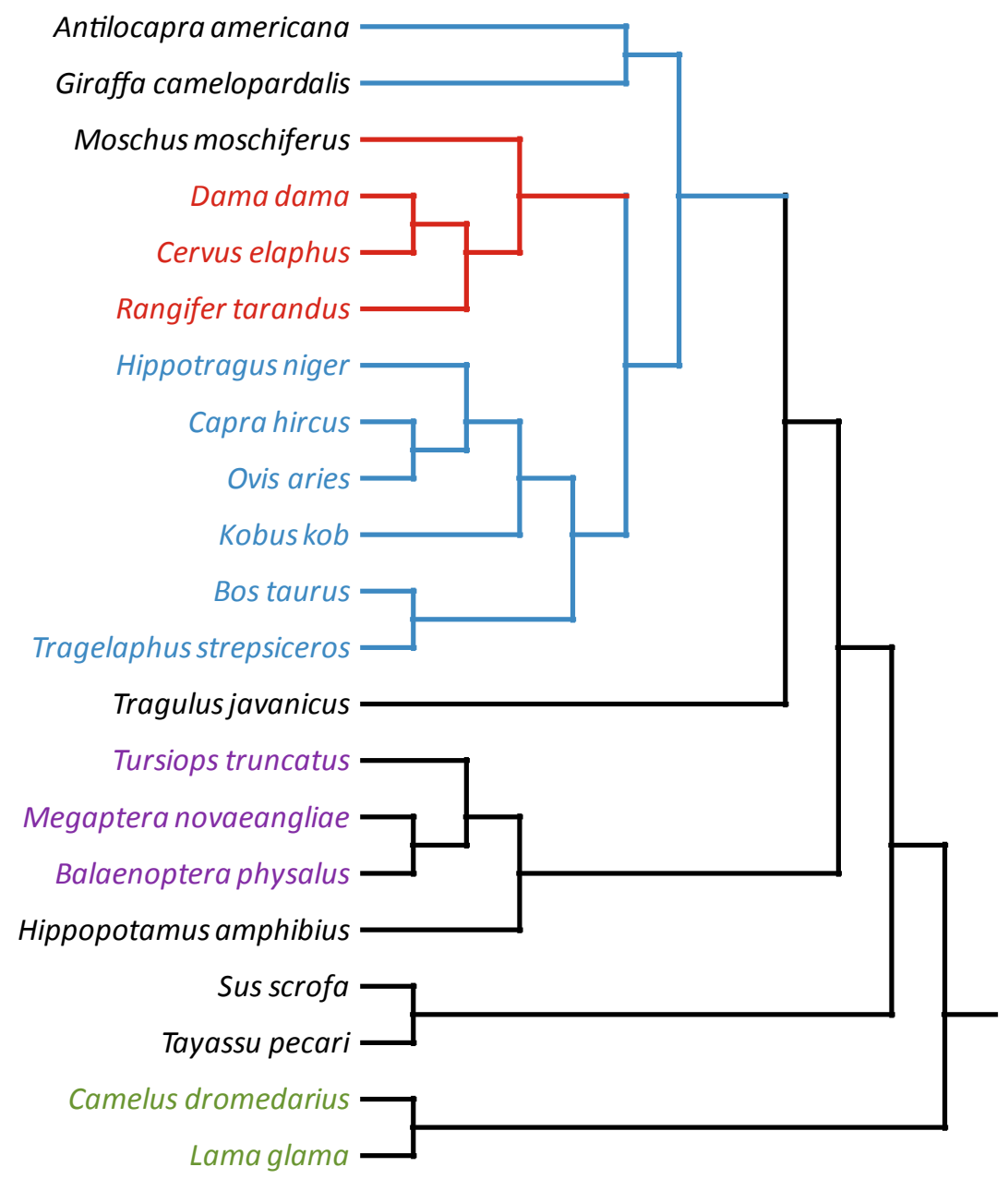

Figure 12. Distribution of the three forms of placental structure found within the Artiodactyla, superimposed on a nucleotide-sequence based phylogenetic tree (Klisch and Mess, 2007). Placental forms are 1.) diffuse (black lines), 2.) polycotyledonary (blue lines) and 3.) oligocotyledonary (red lines). The phylogenetic tree is from Price et al. (2005). Species in family Cervidae are indicated in red text. Species in family Bovidae are indicated in blue text. Species in the Cetacea are indicated in purple text. Species in family Camelidae are indicated in green text. A species which is the only representative for its family is indicated in black text. 
placentomes. This placental form is found in all of the nonruminant artiodactyls (Camelidae, Suidae, Tayassuidae, Cetacea and Hippopotamidae). The polycotyledonary placenta (>50 small placentomes) is the first placentome form to arise. It appears in the ruminant lineage but after the Tragulidae had already diverged so tragulids retain the diffuse, ancestral condition. The oligocotyledonary placenta (5-10 large placentomes) appears later, only in the Cervidae and Moschidae. This suggests that the oligocotyledonary placenta is a condition that evolved from a polycotyledonary ancestor. Thus, a pattern of placental 'evolution' can be determined by comparing placental data among related species in the context of their phylogenetics. It is important to recognize that the accuracy of this approach depends on the accuracy of the phylogenetic tree. In this case, the phylogenetic position of the Moschidae plays an integral part in the interpretation. As described earlier in this manuscript, more recent phylogenies tend to group the Moschidae with the Bovidae. Accurate phylogenetic positioning of the Giraffidae and Antilocapridae are also needed. Once these phylogenetic issues are resolved, the placental data must be reexamined in the context of the more accurate phylogeny. The evolutionary interpretation may change.

The last application of phylogenetics to ruminant reproductive research that I would like to discuss is in the study of speciation. Speciation is the study of how new species arise from an ancestral species. Biologists have wrestled with the question of what constitutes a species for hundreds of years (Coyne and Orr, 2004). Most definitions were based on recognizing morphological differences. In other words, species A could be distinguished from species B by a particular set of physical characteristics. Almost immediately, problems with this approach arise. How different do groups have to be to be classified as different species? How much within species variation can be accepted? Thus, a different type of definition was sought. Ernst Mayr first proposed what most biologists now refer to as the 'biological species concept' (BCS). He defined species as "groups of actual or potentially interbreeding natural populations which are reproductively isolated from other such groups" (Mayr, 1940). While the definition of the term 'species' continues to be debated (Coyne and Orr, 2004), the concept of reproductive isolation is incorporated into most currently accepted definitions. To a reproductive biologist, the BCS is an interesting way to define species since it depends on reproductive compatibility. Species are separated by reproductive barriers. These barriers can be classified as prezygotic (ones that prevent successful fertilization) and postzygotic (ones that prevent the offspring from reproducing). Prezygotic barriers include behavioral and physical incompatibilities that prevent mating. For example, in my home state of Kentucky, it is not unusual to find bison and cattle maintained in the same pastures. Yet, the two rarely interbreed. Even in estrus, Bos taurus cows are not generally appealing to Bison bison bulls, and vice versa. Of course, that is not to say that cross breeding never occurs. It most certainly has and can be 'encouraged' under certain management conditions. The widespread 'contamination' of the bison genome with Bos taurus DNA (Halbert et al., 2005) is proof that this did occur. Using artificial insemination, this behavioral barrier can be completely circumvented. Another great example of prezygotic barriers is in giraffes. Brown et al. (2007) have shown that the modern giraffe population is composed of six, highly segregated, genetic 'subspecies' that rarely interbreed in the wild, even in regions where the geographical ranges of subspecies overlap. Yet these subgroups will readily interbreed in captivity (Ansell, 1971; Gray, 1972; Dagg and Foster, 1982) producing viable, fertile offspring. Clearly, prezygotic reproductive barriers must be at play in nature.

Postzygotic barriers include things like hybrid inviability and hybrid sterility. As will be discussed in great detail below, hybrid sterility is quite common when different species of Bovini are bred to each other. Evolutionarily speaking, reproductive barriers can develop very quickly, often faster than other phenotypic characteristics that allow for the new species 
to be easily distinguishable from the parent species. Thus, one can see why there is so much more variability in reproductive characteristics than in other physiological systems. While the cardiovascular, respiratory and renal systems of the 16 species of Bovini (Figure 8) are essentially the same, each species, by definition, has to differ from the others in at least one reproductive characteristic (i.e. reproductive isolating barriers).

Ruminants may be an ideal model group in which to study the process of speciation. They are numerous and their phylogenies are reasonably well described. Many domesticated forms are available for convenient study. For example, within the Bovini, we have domestic cattle, yaks, mithan, banteng and two species of water buffalo. We also have easy access to tissue from two species of bison. Even with the placement of cattle in question, we have a phylogeny with clear branches that allow for testing hypotheses (Figure 13). Using a molecular clock approach anchored with some very well defined divergence times in the fossil record, we have reasonable estimates for the divergence times of many ruminant species (Bibi, 2013). With a

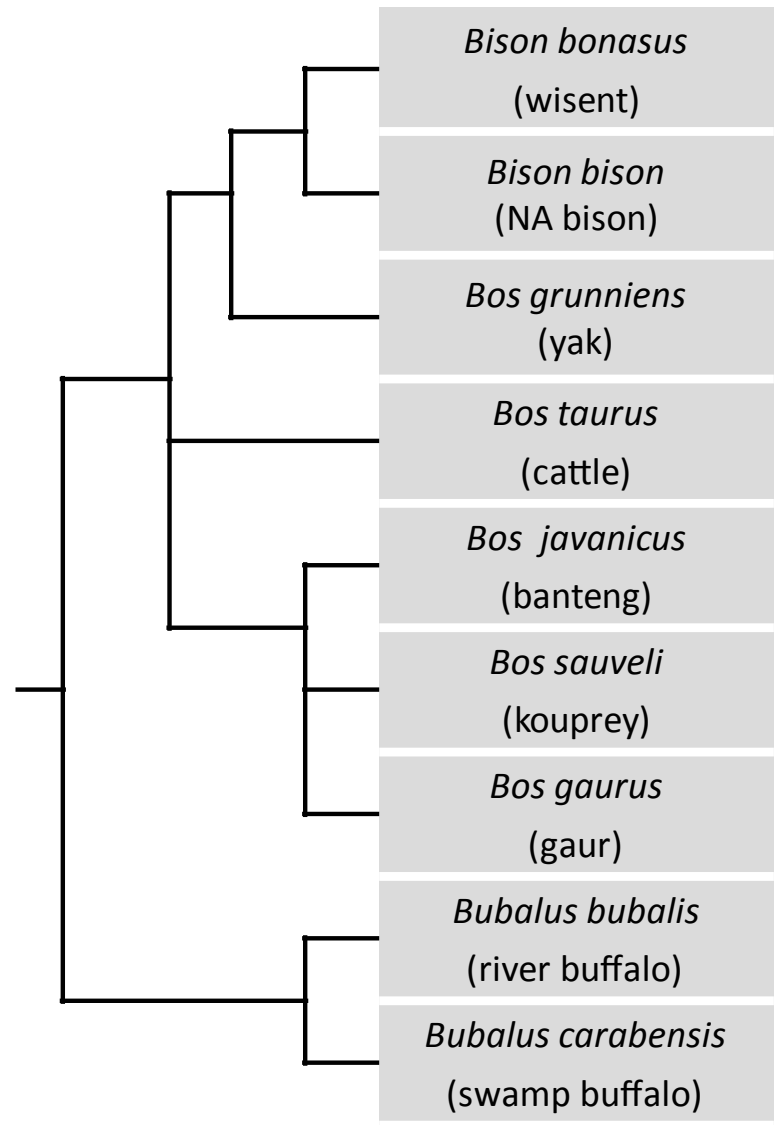

Figure 13. A phylogenetic tree for some common Bovini. This tree can provide a base from which testable hypotheses can developed for identifying reproductive barriers that isolate species. For example, an in vitro fertilization study could be conducted in which the researcher has access to spermatozoa and oocytes from Bison bison, Bos taurus, Bubalus bubalis and Bubalus carabensis. Based on this phylogeny, one would predict and could test the hypothesis that the highest interspecies IVF success rate would be between the Bubalus species, followed by Bos and Bison. Lower rates would be expected between a Bubalus species and either Bos or Bison. 
huge data base of reproductive research on cattle and sheep as a starting point, the possibilities for investigation are enormous.

As noted above, prezygotic reproductive barriers include behavioral incompatibilities. There are numerous anecdotal reports of behavioral compatibility/incompatibility within the Bovini (Felius, 1995). The extent to which this type of barrier has developed needs to be tested experimentally and quantified. A bull from one species can be presented with estrus females from several species to determine if males show species preference. Likewise, an estrus female from one species can be presented with bulls from other species to determine if females show species preference. We would expect that these barriers be the least between species that have diverged from each other most recently.

We can characterize another group of prezygotic barriers to fertilization by doing simple in vitro fertilization studies across species. We can construct a matrix similar to the one shown in Table 2, with species of semen along the top and species of oocyte along the left side. One would expect to see higher rates of fertilization, cleavage and blastocyst formation between species that have diverged from each other more recently. Some of this type of work has already been done (McHugh and Rutledge, 1998; Kochar et al., 2002; Zi et al., 2009; Owiny et al., 2009). If prezygotic barriers are recognized at this level, then the basis for these barriers can be explored. Differences among species in everything from acrosomal enzymes to zona pellucida proteins could be characterized.

Postzygotic reproductive barriers are identified by following the fate of hybrid embryos. Anything that contributes to the failure of hybrids to reproduce would fall into this category. These include developmental problems that lead to hybrid inviability, either prenatally (embryonic and fetal loss) or postnatally (lack of fitness). They also include barriers that lead to hybrid infertility. Many hybridization studies have been conducted using ruminants as subjects. The most extensive work has been done with members of the tribe Bovini. Hybrids of closely related species (ex. Bison bison with Bison bonasus, Bubalus bubalis with Bubalus carabensis) are viable and fertile (Gray, 1972; Basrur, 1986; Bongso and Hilmi, 1982; Hilmi, 1991). Since the precise taxonomic position of Bos taurus remains questionable, hybridization studies involving Bos taurus may be phylogenetically informative. Hybrids of Bos taurus with tropicallyadapted Bovini (Bos javanicus and Bos gaurus) and cold-adapted Bovini (Bos grunniens and Bison bison) are viable. Female offspring are fertile. Male hybrids are not (Deakin et al., 1943; Gray, 1972; Winter et al., 1986; 1988; Tumennasan et al., 1997; Lenstra and Bradley, 1999). Thus, neither hybrid viability nor fertility provides strong support linking Bos taurus to either the tropical- or cold-adapted Bovini groups. The fact that hybrids are viable, and in some cases fertile, suggests that reproductive isolating barriers between these recently-diverged species are still forming. Current species integrity appears to be dependent upon prezygotic barriers.

It is important to keep in mind that these simple qualitative assessments of hybrid outcomes ignore some interesting aspects that may be informative. For example, very few pregnancies go to term when Bos taurus cows are bred to Bison bison bulls. In contrast, a high percentage of hybrid pregnancies go to term when Bos taurus bulls are bred to Bison bison cows (Deakin et al., 1943). More comprehensive hybridizations studies are needed to quantify the percent of successful hybrid breedings and the impact of sire/dam sex on the outcome of hybridization. Hybridization has been attempted between sheep and goats with little success (Warwick and Berry, 1949; Hancock et al., 1968, Hancock et al., 1968). In these studies, fertilization clearly occurs but the pregnancy is terminated within the first 60 days of gestation. This seems reasonable since sheep and goats are quite distantly related (see Figure 7). Hybridization studies have been conducted with many other bovids and cervids (Gray, 1972). These hybridization models may allow us to identify specific postzygotic reproductive barriers, particularly in males. 
Thus, we are at a point where we can begin to extend the enormous body of basic knowledge of reproductive processes in cattle and sheep to other ruminants. As we do this, we can view this comparative data in a phylogenetic context, perhaps leading to a better understanding of basic evolutionary processes, like speciation.

\section{Conclusions}

Our understanding of ruminant phylogenetics has improved tremendously over the past 30 years. We now have very accurate phylogenies for all of the ruminant families. While there are some phylogenetic relationships that remain unclear, these are rare. Reproductive characteristics may prove useful in resolving some of these. More importantly, we can now take advantage of these phylogenies to study how reproductive systems evolved over time. Ruminants are in a unique position to provide fundamental insight into the mechanisms of speciation. There are many species to work with. They are recently-evolved with well characterized phylogenies. They have an enormous degree of reproductive variation. They may be one of the best mammalian models in which to study speciation and other evolutionary processes.

\section{Acknowledgements}

I am extremely grateful to Robert Harmon, chair of the Department of Animal and Food Sciences at the University of Kentucky, for his support and encouragement of my efforts in the study of ruminant phylogenetics. Another administrator may not have recognized the value of this research. I am indebted to my colleagues Jonathan Green, R. Michael Roberts and Jerry Taylor for their common interest and contributions to my research in this area. I sincerely appreciate the critical reviews of this manuscript provided by Jonathan Green, Marcus Clauss and Johannes Lenstra. It was greatly improved through their efforts. This research was supported in part by the Kentucky Agricultural Experiment Station and is published with the approval of the director (publication number 14-07-015).

\section{References}

Ansell WFH 1971 Family Giraffidae. In The Mammals of Africa: An Identification Manual. Pt 15 Pp 13. Eds J Meester \& HW Setzer. Washington, DC: Smithsonian Institution Press

Arnason U, Gullberg A, Gretarsdottir S, Ursing B \& Janke A 2000 The mitochondrial genome of the sperm whale and a new molecular reference for estimating eutherian divergence dates. Journal of Molecular Evolution $\mathbf{5 0}$ 569-578.

Basrur, PK 1986 Bovine hybrids. In Current Therapy in Theriogenology, Vol. 2. Pp. 433-437. Ed D Morrow. Philadelphia, USA: WB Saunders Co.

Bibi F 2013 A multi-calibrated mitochondrial phylogeny of extant Bovidae (Artiodactyla, Ruminantia) and the importance of the fossil record to systematics. BMC Evolutionary Biology 13166.

Bininda-Emonds ORP, Cardillo M, Jones KE, MacPhee RDE, Beck RMD, Grenyer R, Price SA, Vos RA, Gittleman JL \& Purvis A. 2007. The delayed rise of present-day mammals. Nature 446 507-512.
Bland KP \& Kitchener AC 2001 The anatomy of the penis of a sperm whale (Physeter catodon L., 1758). Mammal Review 31 239-244.

Bongso TA \& Hilmi M 1982 Chromosome banding homologies of a tandem fusion in river, swamp and crossbred buffaloes (Bubalus bubalis). Canadian Journal of Genetics and Cytology 24 667-673.

Bradley DG, MacHugh DE, Cunningham P \& Loftus RT 1996 Mitochondrial diversity and the origins of African and European cattle. Proceedings of the National Academy of Sciences USA 93 5131-5135.

Brooke V 1878 On the classification of the Cervidae, with a synopsis of the existing species. Proceedings of the Zoological Society of London pp. 833-928, figs. 1-19, pl. LV.

Brown DM, Brenneman RA, Koepfli KP, Pollinger JP, Mila B, Georgiadis NJ, Louis EE, Grether GF, Jacobs DK \& Wayne RK 2007 Extensive population genetic structure in the giraffe. BMC Biology 557.

Buntjer JB, Otsen M, Nijman IJ, Kuiper MTR \& Lenstra 
JA 2002 Phylogeny of bovine species based on AFLP fingerprinting. Heredity $\mathbf{8 8}$ 46-51.

Burt WH \& Grossenheider RP 1976. A Field Guide to the Mammals ( $3^{\text {rd }}$ ed.) Boston, USA: Houghton Mifflin Co.

Camin JH \& Sokal RR 1965 A method for deducing branching sequences in phylogeny. Evolution 19 311-326.

Canevari M \& Vaccaro O 2007 Guía de Mamíferos del sur de América del Sur. Buenos Aires, Argentina: Literature of Latin America Inc.

Cap H, Deleporte P, Joachim J \& Reby D 2008. Male vocal behavior and phylogeny in deer. Cladistics 24 917-931.

Chakrabarty A, MacLean II JA, Hughes AL, Roberts RM \& Green JA 2006 Rapid evolution of the trophoblast Kunitz domain proteins (TKDPs)- a multigene family in ruminant ungulates. Journal of Molecular Evolution 63 274-282.

Clutton-Brock J 1981 Domesticated Animals from Early Times. Austin, Texas, USA: University of Texas Press.

Coyne JA \& Orr HA 2004. Speciation. Sunderland, MA, USA: Sinauer Associates Inc.

Dagg AI \& Foster JB 1982 The Giraffe: its Biology, Behavior, and Ecology. Melbourne, FL: Krieger Publishing Company.

Darwin C 1859 On the origin of species by means of natural selection, or the preservation of favoured races in the struggle for life (1st ed.). Chapter IV. London: John Murray Publishers.

Davis EB, Brakora KA \& Lee AH 2011. Evolution of ruminant headgear: a review. Proceedings of the Royal Society $B$ 278 2857-2865.

Deakin A, Muir GW, Smith AG \& MacLellan AS 1943 Hybridization of domestic cattle and buffalo (Bison americanus). Progress report of the Wainwright Experiment 1935-1941. Experimental Farms Service Report. Dominion of Canada, Department of Agriculture.

Decker JE, Pires JC, Conant GC, McKay SD, Heaton MP, Chen K, Cooper A,Vilkki J, Seabury CM, Caetano AR, Johnson GS, Brenneman RA, Hanotte O, Eggert LS, Wiener P, Kim JJ, Sonstegard TS, van Tassell CP, Neibergs HL, McEwan JC, Brauning R, Coutinho LL, Babar ME, Wilson GA, McClure MC, Rolf MM, Kim JW, Schnabel RD \& Taylor JF 2009. Resolving the evolution of extant and extinct ruminants with high-throughput phylogenomics. Proceedings of the National Academy of Sciences USA 106 18644-18649.

Dorn CG 1995 Application of reproductive technologies in North American Bison (Bison bison). Theriogenology 43 13-20.

Dorst J \& Dandelot P 1972 A Field Guide to the Larger Mammals of Africa. ( $2^{\text {nd }}$ ed) London: Collins Publishing Inc.

Drost M, Wright JM \& Elsden RP 1986 Intergeneric embryo transfer between water buffalo and domestic cattle. Theriogenology 25 13-23.

Felius M 1995 Cattle Breeds-An Encyclopedia. Doetinchem, NL: Misset Uitgeverij BV pub.

Felsenstein J 1985 Confidence limits on phylogenies: An approach using the bootstrap. Evolution 39 783-791.

Gatesy J 1997 More DNA support for a Cetacea/ Hippopotamidae clade: the blood-clotting protein gene $\gamma$-fibrinogen. Molecular Biology and Evolution 14 537-543.
Gatesy J, Milinkovitch M, Waddell V \& Stanhope M 1999 Stability of cladistic relationships between Cetacea and higher-level Artiodactyla taxa. Systematic Biology $\mathbf{4 8}$ 6-20.

Graur D \& Higgins DG 1994 Molecular evidence for the inclusion of cetaceans within the order Artiodactyla. Molecular Biology and Evolution 11 357-364.

Gray AP 1972 Mammalian hybrids. A checklist with bibliography. Technical Communication no. 10 (revised) pp 1-262. Edinburgh: Commonwealth Bureau of Animal Breeding and Genetics.

Gray JE 1821 On the natural arrangement of vertebrate mammals. London Medical Repository 15(1)296-310.

Halbert ND, Ward TJ, Schnabel RD, Taylor JF \& Derr JN 2005 Conservation genomics: disequilibrium mapping of domestic cattle chromosomal segments in North American bison populations. Molecular Ecology 14 2343-2362.

Hall BK 2003 Balfour, Garstang and de Beer: The first century of evolutionary embryology. American Zoologist $\mathbf{4 0}$ 718-728.

Hancock JL \& McGovern PT 1968 Transfer of goat x sheep hybrid eggs to sheep and reciprocal transfer of eggs between sheep and goats. Research in Veterinary Science 9 411-415.

Hancock JL, McGovern PT \& Stamp JT 1968 Failure of gestation of goat $x$ sheep hybrids in goats and sheep. Journal of Reproduction and Fertility (Supplement 3) 29-36.

Harrison RJ, Johnson FR \& Young BA 1970 The oesophagus and stomach of dolphins (Tursiops, Delphinus, Stenella). Journal of Zoology 160 377-390.

Hasegawa M \& Adachi J 1996 Phylogenetic position of cetaceans relative to artiodactyls: reanalysis of mitochondrial and nuclear sequences. Molecular Biology and Evolution 13 710-717.

Hassanin A, An J, Ropiquet A, Nguyen TT \& Couloux A 2013 Combining multiple autosomal introns for studying shallow phylogeny and taxonomy of Laurasiatherian mammals: Application to the tribe Bovini (Cetartiodactyla, Bovidae). Molecular Phylogenetics and Evolution 66 766-775.

Hassanin A, Delsuc F, Ropiquet A, Hammer C, van Vuuren BJ, Matthee C, Ruiz-Garcia M, Catzeflis F, Areskong V, Nguyen TT \& Couloux A 2012 Pattern and timing of diversification of Cetartiodactyla (Mammalia, Laurasiatheria), as revealed by a comprehensive analysis of mitochondrial genomes. Comptes Rendus Biologies 335 32-50.

Hassanin A \& Ropiquet A 2007 Resolving a zoological mystery: the kouprey is a real species. Proceedings of the Royal Society B 274 2849-2855.

Hernandez Fernandez M \& Vrba E 2005 A complete estimate of the phylogenetic relationships in Ruminantia: a dated species-level supertree of the extant ruminants. Biological Reviews 80 269-302.

Herwig RP \& Staley JT 1986 Anaerobic bacteria from the digestive tract of North Atlantic fin whales (Balaenoptera physalus). FEMS Microbial Ecology 38 361-371.

Herwig RP, Staley JT, Nerini MK \& Braham HW 1984 Baleen whales: preliminary evidence for forestomach microbial 
fermentation. Applied Environmental Microbiology 47 421-423.

Hilmi M 1991 Semen characteristics of different buffalo genotypes. In Buffalo and Goats in Asia: genetic diversity and its application. Proceedings of a workshop, Kuala Lumpur, Malaysia 10-14 February, 1991. Ed NM Tulloh. ACIAR Proceedings 34 99-101.

Hofmann RR 1973 The ruminant stomach: stomach structure and feeding habits of east African game ruminants. Nairobi, Kenya: East African Literature Bureau Publishers.

Irwin D \& Arnason U 1994 Cytochrome b gene of marine mammals: phylogeny and evolution. Journal of Mammalian Evolution 2 37-55.

Jiang L, Wang G, Tan S, Gong S, Yang M, Peng Q, Peng R \& Zou F 2013 The complete mitochondrial genome sequence analysis of Tibetan argali (Ovis ammon hodgsoni): Implications of Tibetan argali and Gansu argali as the same subspecies. Gene 521 24-31.

Kingdon J 1997 The Kingdon Field Guide to African Mammals. San Diego, USA: Natural World, Academic Press.

Klisch K \& Mess A 2007 Evolutionary differentiation of cetartiodactyl placentae in the light of the viviparity-driven conflict hypothesis. Placenta 28 353-360.

Kochar HPS, Appa Rao KBC, Luciano AM, Totey SM, Gandolfi F, Basrur PK \& King WA 2002 In vitro production of cattle-water buffalo (Bos taurus-Bubalus bubalis) hybrid embryos. Zygote 10 155-162.

Langer P 1974 Stomach evolution in the Artiodactyla. Mammalia 38 295-314.

Langer P 1974. Macroscopic anatomy of the stomach of the Hippopotamidae (Gray, 1821). Anatomia, Histologia, Embrologia (Zentralblatt fur Vetrinarmedizin Reihe C) 4 334-359.

Lenstra JA and Bradley DG 1999 Systematics and phylogeny of cattle. In The Genetics of Cattle, pp 1-14. Ed RFA Ruvinsky. Wallingford, UK: CAB International.

Lusseau D 2003 The emergence of cetaceans: phylogenetic analysis of male social behaviour supports the Cetartiodactyla clade. Journal of Evolutionary Biology 16 531-535.

Mayr E 1940 Speciation phenomena in birds. American Naturalist 74 249-278.

MacEachern S, McEwan J \& Goddard M 2009a Phylogenetic reconstruction and the identification of ancient polymorphism in the Bovini tribe (Bovidae, Bovinae). BMC Genomics 10177

MacEachern S, McEwan J, McCulloch A, Mather A, Savin K \& Goddard M 2009b Molecular evolution of the Bovini tribe (Bovidae, Bovinae): Is there evidence of rapid evolution or reduced selective constraint in domestic cattle? BMC Genomics 10179

McHugh JA \& Rutledge JJ 1998 Heterologous fertilization to characterize spermatozoa of the genus Bos. Theriogenology 50 185-193.

McKenna MC \& Bell SK 1997 Classification of Mammals: above the species level. New York, USA: Columbia University Press.

Mead JG 2007 Stomach anatomy and use in defining systematic relationships of the cetacean family Ziphiidae (beaked whales). Anatomical Record 290 581-595.
Milne-Edwards A 1864 Recherches anatomiques, zoologiques et paléontologiques sur la famille des chevrotains. Annales de Science Naturelle Paris 5 49-167.

Monde des Mammiferes (web site): http://monde.des. mammiferes.free.fr/Placentaires/Artiodactyla/Moschidae/ Moschidae.php

Montgelard C, Catzeflis FM \& Douzery E 1997 Phylogenetic relationships of artiodactyls and cetaceans as deduced from the comparison of cytochrome $b$ and 12S rRNA mitochondrial sequences. Molecular Biology and Evolution 14 550-559.

Mossman HW 1987 Vertebrate fetal membranes: comparative ontogeny and morphology, evolution, phylogenetic significance, basic functions, research opportunities. London, UK: Macmillan Press.

O'Leary MA \& Gatesy J 2008 Impact of increased sampling on the phylogeny of Cetartiodactyla (Mammalia): combined analysis including fossils. Cladistics 24 397442.

O'Leary MA, Bloch JI, Flynn JJ, Gaudin TJ, Giallombardo A, Giannini NP, Goldberg SL, Kraatz BP, Luo ZX, Meng J, Ni X, Novacek MJ, Perini FA, Randall ZS, Rougier GW, Sargis EJ, Silcox MT, Simmons NB, Spaulding M, Velazco PM, Weksler M, Wible JR, \& Cirranello AL. 2013. The placental mammal ancestor and the post-K-Pg radiation of placentals. Science 339 662-667.

Olsen MA \& Mathiesen SD 1996 Production rates of volatile fatty acids in the minke whale (Balenoptera acutorostrata) forestomach. British Journal of Nutrition 75 21-31.

Owiny OD, Barry DM, Agaba M \& Godke RA 2009 In vitro production of cattle $\mathrm{x}$ buffalo hybrid embryos using cattle oocytes and African buffalo (Synceros caffer caffer) epididymal sperm. Theriogenology 71 884-894.

Price SA, Bininda-Emonds ORP \& Gittleman JL 2005 A complete phylogeny of the whales, dolphins and even toed hoofed mammals (Certartiodactyla). Biological Reviews 80 445-473.

Reid FA 2006 A Field Guide to Mammals of North America. $\left(4^{\text {th }}\right.$ ed). Boston, USA: Houghton Mifflin Co.

Romer AS \& Parsons TS 1977 The Vertebrate Body ( $5^{\text {th }}$ ed), pg 88. Philadelphia, USA: W.B. Saunders Co.

Rössner GE 2007 Family Tragulidae. In The Evolution of Artiodactyls, pp 213-220. Eds DR Prothero \& SE Foss. Baltimore, MD, USA: Johns Hopkins University Press.

Schwarm A, Ortmann S, Rietschel W, Kuhne R, Wibbelt G \& Clauss M 2010 Function, size and form of the gastrointestinal tract of the collared Pecari tajacu (Linnaeus 1758) and white-lipped peccary Tayassu pecari (Link 1795). European Journal of Wildlife Research 56 569-576.

Shimamura M, Abe H, Nikaido M, Ohshima K \& Okada N 1999 Genealogy of families of SINEs in cetaceans and artiodactyls: the presence of a huge superfamily of tRNA ${ }^{\text {glu }}$-derived families of SINEs. Molecular Biology and Evolution 16 1046-1060.

Simpson GG 1945 The principals of classification and a classification of mammals. Bulletin of the American Museum of Natural History 85 1-350.

Slijper EJ 1966 Functional morphology of the reproductive system in Cetacea. In Whales, Dolphins and Porpoises. Ed SK Norris. Berkeley, USA: University of California Press. 
Spaulding M, O'Leary MA \& Gatesy J 2009 Relationships of Cetacea (Artiodactyla) among mammals: Increased taxon sampling alters interpretations of key fossils and character evolution. PLoS ONE 4(9) e7062. Doi:10.1371/journal. pone.0007062

Stevens CE \& Hume ID 1995 Comparative physiology of the vertebrate digestive system, 2nd ed. Cambridge, UK: Cambridge University Press.

Stover J, Evans J \& Dolensek EP 1981 Interspecies embryo transfer from the gaur to domestic Holstein. Proceedingsof the American Association of Zoo Veterinarians, Seattle WA: 122-124

Summers PM, Shelton JN \& Edwards J 1983 The production of mixed-species Bos taurus - Bos indicus twin calves. Animal Reproduction Science 6 79-89.

Tanaka K, Solis CD, Masangkay JS, Maeda KI, Kawamoto Y \& Namikawa T 1996 Phylogenetic relationship among all living species of the genus Bubalus based on DNA sequences of the cytochrome $b$ gene. Biochemical Genetics 34 443-452.

Telugu BP, Walker AM \& Green JA 2009 Characterization of the bovine pregnancy-associated glycoprotein gene family - analysis of gene sequences, regulatory regions within the promoter and expression of selected genes. BMC Genomics 10185.

Tinbergen $\mathbf{N} 1959$ Comparative studies of the behavior of gulls. Behaviour 15:1-70.

Tumennasan K, Tuya T, Hotta Y, Takase H, Speed RM \& Chandley AC 1997 Fertility investigations in the F1 hybrid and backcross progeny of cattle (Bos Taurus) and yak (B. grunniens) in Mongolia. Cytogenetics and Cell Genetics 78 69-73.

Ushizawa K \& Hashizume K 2006 Biology of the prolactin family in bovine placenta. II. Bovine prolactin-related proteins: Their expression, structure and proposed roles. Animal Science Journal 77 18-27.

Ushizawa K, Takahashi T, Hosoe M, Ohkoshi K \& Hashizume K 2007 Expression and characterization of novel ovine orthologs of bovine placental prolactinrelated proteins. BMC Molecular Biology 895.
Vallenas A, Cummings JF \& Munnell JF 1971 A gross study of the compartmentalized stomach of two new-world camelids, the Ilama and guanaco. Journal of Morphology 134 399-424.

Verkaar ELC, Nijman IJ, Beeke M, Hanekamp E \& JA Lenstra 2004 Maternal and paternal lineages in cross-breeding bovine species. Has wisent a hybrid origin? Molecular Biology and Evolution 21 1165-1170.

Waddell PJ, Okada N \& Hasegawa M 1999 Towards resolving the interordinal relationships of placental mammals. Systematic Biology 48 1-5.

Walker AM \& Roberts RM 2009 Characterization of the bovine type I IFN locus: rearrangements, expansions and novel subfamilies. BMC Genomics 10187.

Warwick BL \& Berry RO 1949 Inter-generic and intra-specific embryo transfers in sheep and goats Journal of Heredity 40 297-303.

Webb SD \& Taylor BE 1980 The phylogeny of hornless ruminants and a description of the cranium of Archaeomeryx. Bulletin of the American Museum of Natural History 167 117-158.

Winter H, Mayr B, Schleger W, Dworak E, Krutzler J \& Kalat M 1986 Genetic characterisation of the mithun (Bos frontalis) and studies of spermatogenesis, blood groups and haemoglobins of its hybrids with Bos indicus. Research in Veterinary Science 40 8-17.

Winter H, Kalat M, Mayr B, Dworak E \& Schleger W 1988 Mithun cross siri hybrids: cyto- and immunogenetic examinations and characterisation of abnormal spermatogenesis. Research in Veterinary Science $\mathbf{4 5}$ 86-100.

Zi XD, Yin RH, Chen SW, Liang GN, Zhang DW \& Guo CH 2009 Developmental competence of embryos derived from reciprocal in vitro fertilization between yak (Bos grunniens) and cattle (Bos taurus). Journal of Reproduction and Development 55 480-483. 
